\title{
Discovery of TAK-925 as a Potent, Selective and Brain-Penetrant Orexin 2 Receptor Agonist
}

Tatsuhiko Fujimoto, $\nmid$ Kentaro Rikimaru, $\dagger$ Koichiro Fukuda, $\dagger$ Hiromichi Sugimoto, $\dagger$ Kei Masuda, $\dagger$ Norio Ohyabu, $\dagger$ Yoshihiro Banno, $†$ Norihito Tokunaga, $\dagger^{*}$ Tetsuji Kawamoto, $†$ Yoshihide Tomata, $\uparrow$ Yasumi Kumagai, $\uparrow$ Motoo Iida, $\uparrow$ Yoichi Nagano, $\uparrow$ Mariko Yoneyama-Hirozane, $\dagger$ Yuji Shimizu, $\uparrow$ Katsunori Sasa, $\uparrow$ Takashi Ishikawa, $\dagger$ Hiroshi Yukitake, $\dagger$ Mitsuhiro Ito, $\dagger$ Kazunobu Aoyama, †́ and Takahiro Matsumoto $†$

† Research, Takeda Pharmaceutical Company Limited, 26-1, Muraoka-Higashi 2-Chome, Fujisawa Kanagawa 251-8555, Japan

\section{Corresponding author \\ Norihito Tokunaga Ph.D.}

Research, Takeda Pharmaceutical Company Limited, 26-1 Muraoka-Higashi 2-Chome, Fujisawa, Kanagawa 2518555, Japan

Phone No: +81-466-32-1218

Email Address: norihito.tokunaga@takeda.com

ORCID: 0000-0002-5693-6858 
Table of contents

Analytical HPLC traces (compound purity in HPLC) S3

$\begin{array}{lr}\text { Chemical synthesis procedures } & \text { S9 }\end{array}$

Calcium flux assay (in vitro agonistic activity of OX2R and OX1R) S36

Transcellular transport study using a transporter-expression system $\quad$ S37

Measurement of plasma and brain concentration of compound 16 in mice S38

Evaluation of wakefulness time measurement of compound 16 in mice S39

${ }^{1} \mathrm{H}$ NMR and ${ }^{13} \mathrm{C}$ NMR charts of compound 16

Single-crystal X-ray structure analysis of compound $16 \quad$ S41

$\begin{array}{ll}\text { References } & \text { S42 }\end{array}$ 


\section{Analytical HPLC traces (compound purity in HPLC)}

Analytical HPLC method. Analytical HPLC was performed with Corona Charged Aerosol Detector (CAD), Nano quantity analyte detector (NQAD), or photo diode array detector. The column was a Capcell Pak C18AQ (50 mm $\times 3.0 \mathrm{~mm}$ I.D., Shiseido, Japan) or L-column 2 ODS (30 $\mathrm{mm} \times 2.0 \mathrm{~mm}$ I.D., CERI, Japan) with a temperature of $50{ }^{\circ} \mathrm{C}$ and a flow rate of $0.5 \mathrm{~mL} / \mathrm{min}$. Mobile phase $\mathrm{A}$ and $\mathrm{B}$ under a neutral condition were a mixture of $50 \mathrm{mmol} / \mathrm{L}$ ammonium acetate, water, and acetonitrile $(1: 8: 1, \mathrm{v} / \mathrm{v} / \mathrm{v})$ and a mixture of $50 \mathrm{mmol} / \mathrm{L}$ ammonium acetate and acetonitrile $(1: 9, \mathrm{v} / \mathrm{v})$, respectively. The ratio of mobile phase B was increased linearly from $5 \%$ to $95 \%$ over 3 min, $95 \%$ over the next 1 min. Mobile phase $\mathrm{A}$ and $\mathrm{B}$ under an acidic condition were a mixture of $0.2 \%$ formic acid in $10 \mathrm{mmol} / \mathrm{L}$ ammonium formate and $0.2 \%$ formic acid in acetonitrile, respectively. The ratio of mobile phase B was increased linearly from $14 \%$ to $86 \%$ over $3 \mathrm{~min}, 86 \%$ over the next $1 \mathrm{~min}$. The purities of all tested compounds were $>95 \%$ as determined by elemental analyses within $\pm 0.4 \%$ of the calculated values or analytical HPLC.

\section{Compound 3}

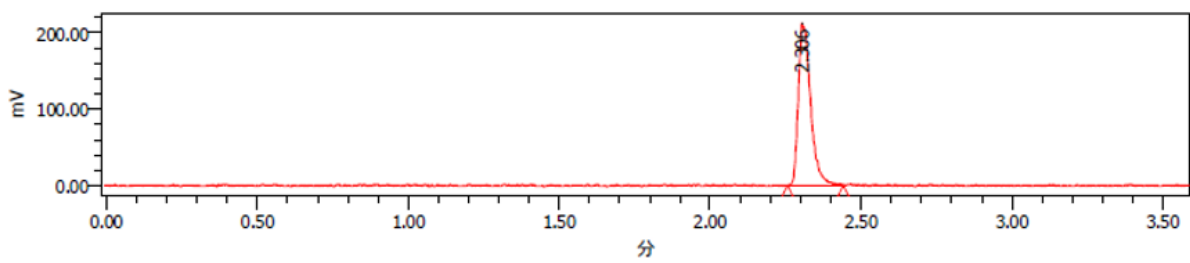

\begin{tabular}{|c|c|c|c|}
\hline & $\begin{array}{c}\text { tR } \\
(\text { 分 })\end{array}$ & $\begin{array}{c}\text { Area } \\
(\mu \mathrm{V} \text { 秒 })\end{array}$ & $\%$ Area \\
\hline 1 & 2.334 & 694020 & 100.00 \\
\hline
\end{tabular}

\section{Compound 4}

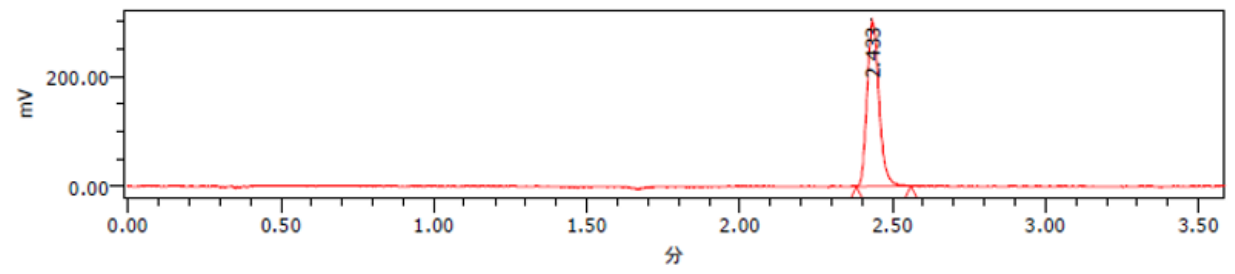

\begin{tabular}{|c|c|c|c|}
\hline & $\begin{array}{c}\text { tR } \\
(\text { 分 })\end{array}$ & $\begin{array}{c}\text { Area } \\
(\mu \mathrm{V} \text { 秒 })\end{array}$ & $\%$ Area \\
\hline 1 & 2.433 & 824174 & 100.00 \\
\hline
\end{tabular}




\section{Compound 5}

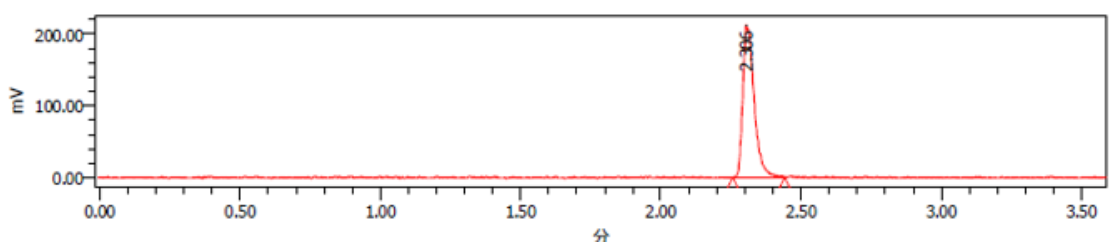

\begin{tabular}{|c|c|c|c|}
\hline & $\begin{array}{c}\text { tR } \\
(\text { 分 })\end{array}$ & $\begin{array}{c}\text { Area } \\
(\boldsymbol{\mu V} \text { 秒 })\end{array}$ & $\%$ Area \\
\hline 1 & 2.306 & 599429 & 100.00 \\
\hline
\end{tabular}

\section{Compound 6}

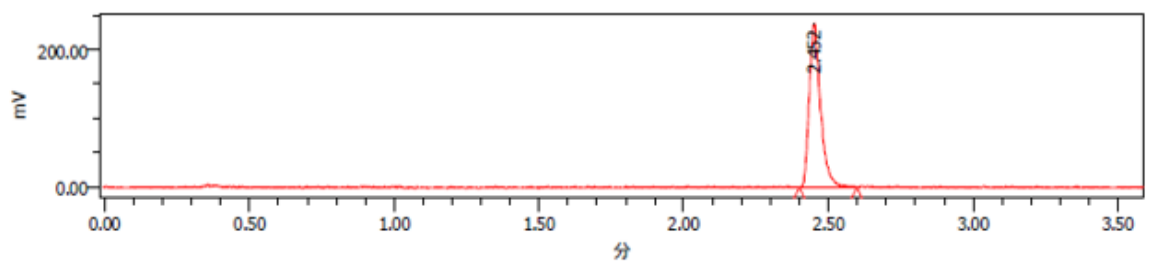

\begin{tabular}{|c|c|c|c|}
\hline & $\begin{array}{c}\text { tR } \\
(\text { 分 })\end{array}$ & $\begin{array}{c}\text { Area } \\
(\mu \mathrm{V} \text { 秒 })\end{array}$ & $\%$ Area \\
\hline 1 & 2.452 & 640253 & 100.00 \\
\hline
\end{tabular}

\section{Compound 7}

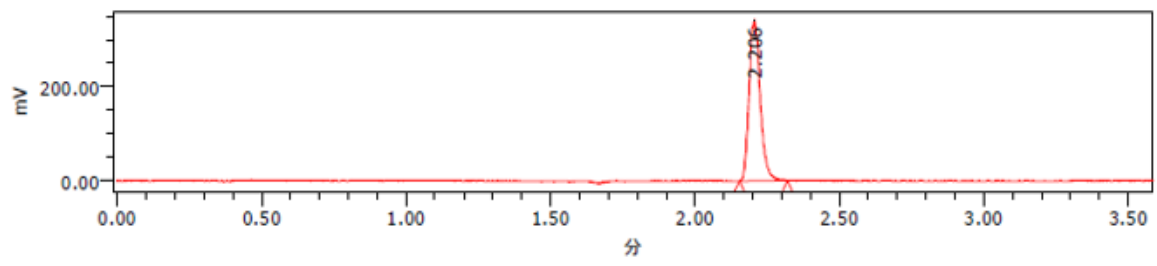

\begin{tabular}{|c|c|c|c|}
\hline & $\begin{array}{c}\mathrm{tR} \\
(\text { 分 })\end{array}$ & $\begin{array}{c}\text { Area } \\
(\boldsymbol{\mu} \mathrm{V} \text { 秒 })\end{array}$ & $\%$ Area \\
\hline 1 & 2.206 & 908748 & 100.00 \\
\hline
\end{tabular}

\section{Compound 8}

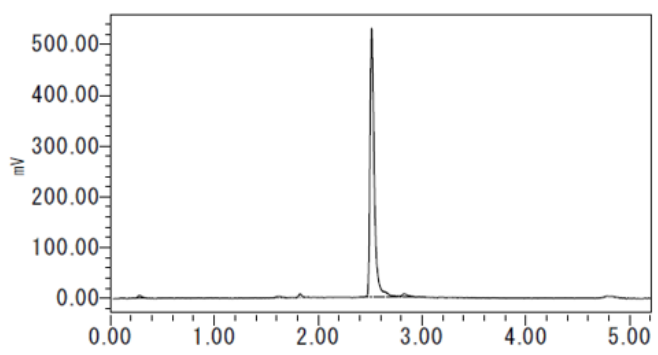

Result of Analys is

\begin{tabular}{|r|r|r|r|r|}
\hline & $\begin{array}{l}\text { Retention } \\
\text { Tme } m \text { } n\end{array}$ & $\begin{array}{l}\text { Peak area } \\
(\mu \nu \times \text { sec }\end{array}$ & $\begin{array}{l}\text { Divisinal } \\
\text { method }\end{array}$ & \% of Area \\
\hline 1 & 0.286 & 14891 & bb & 0.94 \\
\hline 2 & 1.621 & 9517 & bb & 0.60 \\
\hline 3 & 1.826 & 15522 & BB & 0.98 \\
\hline 4 & 2.516 & 1510570 & BB & 95.76 \\
\hline 5 & 2.643 & 4112 & tt & 0.26 \\
\hline 6 & 2.831 & 22855 & IT & 1.45 \\
\hline
\end{tabular}




\section{Compound 9}

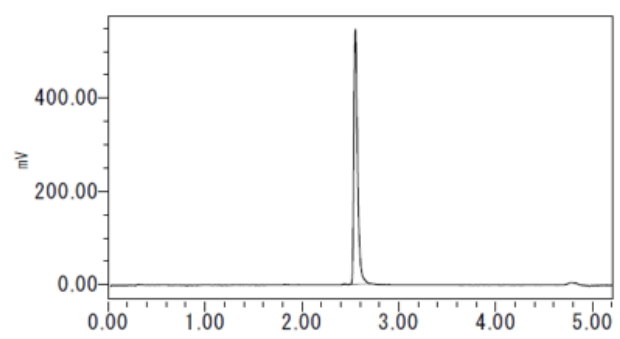

Result of Analys is

\begin{tabular}{|r|r|r|l|r|}
\hline & $\begin{array}{r}\text { Retention } \\
\text { T m e } m \boldsymbol{n} \text { ) }\end{array}$ & $\begin{array}{l}\text { Peak area } \\
(\mu \mathrm{V} \times \mathrm{sec})\end{array}$ & $\begin{array}{l}\text { D ivis ional } \\
\text { m ethod }\end{array}$ & \% of Area \\
\hline 1 & 2.443 & 3997 & bb & 0.27 \\
\hline 2 & 2.552 & 1456093 & B B & 99.73 \\
\hline
\end{tabular}

\section{Compound 10}

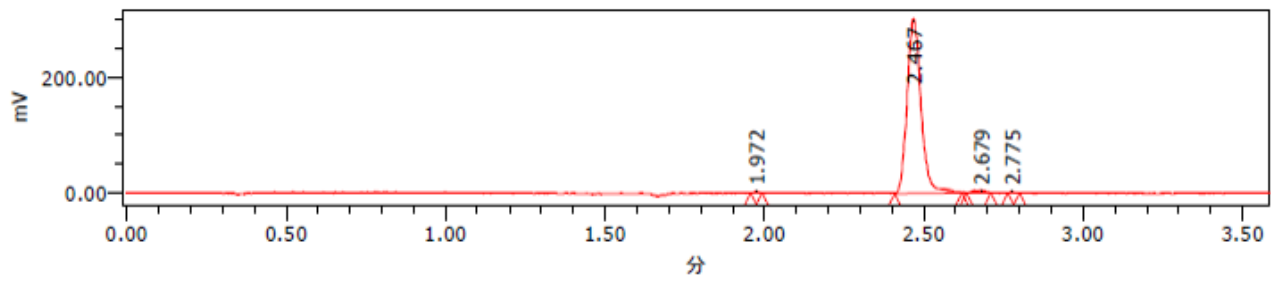

\begin{tabular}{|l|c|r|r|}
\hline & $\begin{array}{c}\text { tR } \\
(\text { 分 })\end{array}$ & $\begin{array}{c}\text { Area } \\
\left(\mu \mathrm{V} \mathbf{y}^{\prime}\right)\end{array}$ & $\%$ Area \\
\hline 1 & 1.972 & 2800 & 0.30 \\
\hline 2 & 2.467 & 911859 & 98.36 \\
\hline 3 & 2.679 & 9551 & 1.03 \\
\hline 4 & 2.775 & 2893 & 0.31 \\
\hline
\end{tabular}

\section{Compound 11}

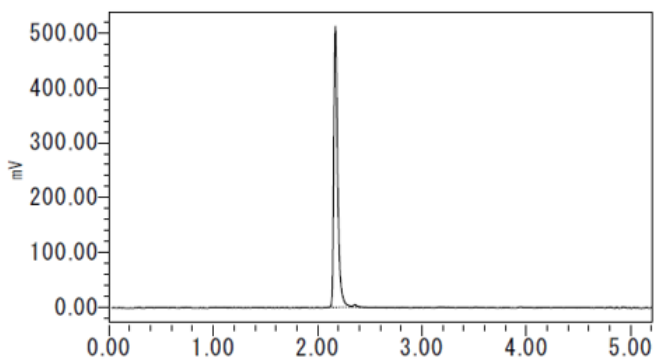

Result of Analys is

\begin{tabular}{|c|c|c|c|c|}
\hline & $\begin{array}{l}\text { Retention } \\
\text { I me } m i n)\end{array}$ & $\begin{array}{l}\text { Peak area } \\
(\mu \vee \times \text { sec })\end{array}$ & $\begin{array}{l}\text { Divisional } \\
\text { method }\end{array}$ & $\%$ of Area \\
\hline 1 & 2.171 & 1336868 & BB & 99.46 \\
\hline 2 & 2.359 & 7307 & TT & 0.54 \\
\hline
\end{tabular}

\section{Compound 12}

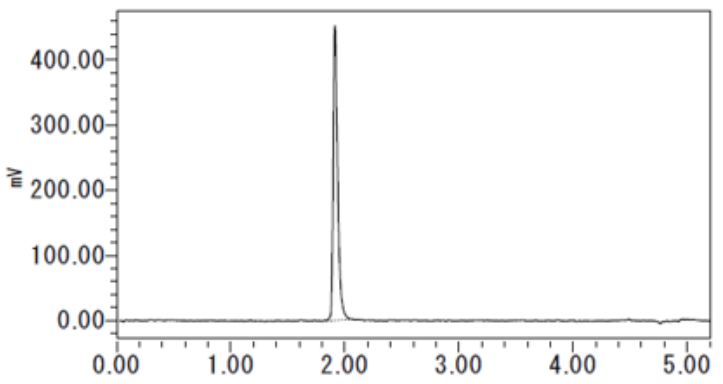

\begin{tabular}{|c|c|c|c|c|}
\hline \multicolumn{5}{|c|}{ Result of Analvs is } \\
\hline & $\begin{array}{l}\text { Retention } \\
\text { I me } \mathrm{m} \text { ) }\end{array}$ & $\begin{array}{l}\text { Peak area } \\
(\mu V \times \sec )\end{array}$ & $\begin{array}{c}\text { D isisional } \\
\text { method }\end{array}$ & $\%$ of Area \\
\hline 1 & 1.914 & 1246586 & VB & 100.00 \\
\hline
\end{tabular}




\section{Compound 13}

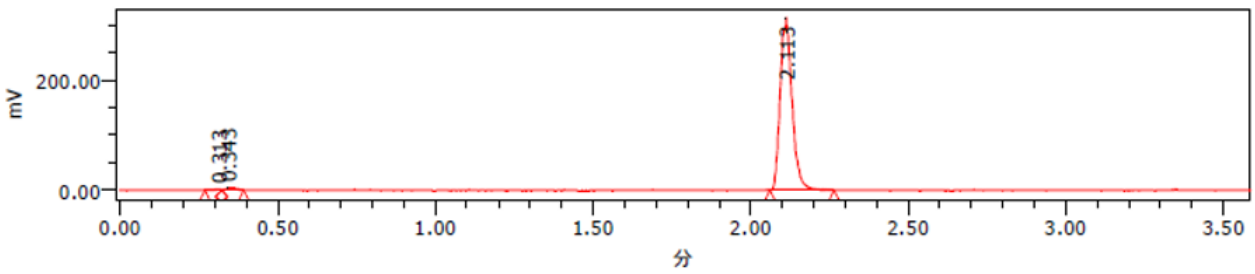

\begin{tabular}{|l|c|r|r|}
\hline & $\begin{array}{c}\mathrm{tR} \\
(\text { 分 })\end{array}$ & $\begin{array}{c}\text { Area } \\
(\mu \mathrm{N} \text { 秒 })\end{array}$ & $\%$ Area \\
\hline 1 & 0.313 & 3184 & 0.38 \\
\hline 2 & 0.343 & 10632 & 1.27 \\
\hline 3 & 2.113 & 822293 & 98.35 \\
\hline
\end{tabular}

\section{Compound 13a}

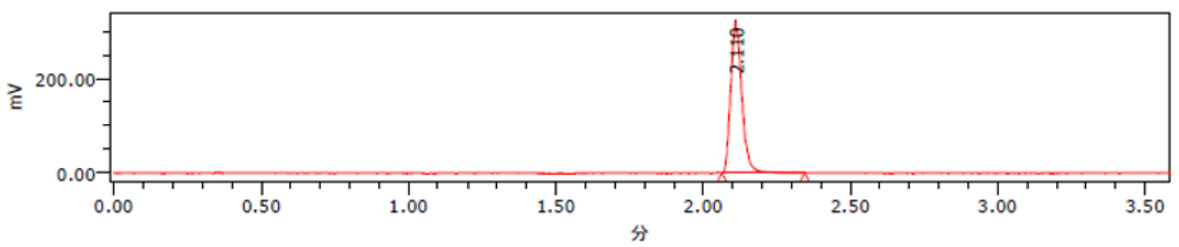

\begin{tabular}{|c|c|c|c|}
\hline & $\begin{array}{c}\text { tR } \\
(\text { 分 })\end{array}$ & $\begin{array}{c}\text { Area } \\
(\mu \mathrm{V} \text { 秒 })\end{array}$ & $\%$ Area \\
\hline 1 & 2.110 & 851075 & 100.00 \\
\hline
\end{tabular}

\section{Compound 13b}

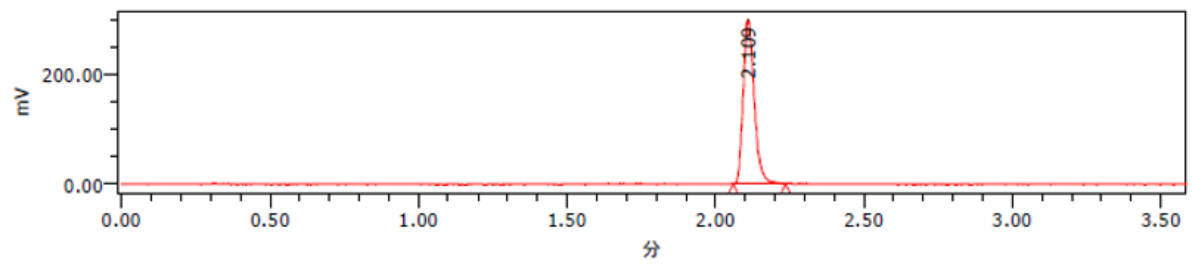

\begin{tabular}{|c|c|c|c|}
\hline & $\begin{array}{c}\text { tR } \\
(\text { 分 })\end{array}$ & $\begin{array}{c}\text { Area } \\
(\mu \mathrm{V} \text { 秒 })\end{array}$ & $\%$ Area \\
\hline 1 & 2.109 & 772149 & 100.00 \\
\hline
\end{tabular}

\section{Compound 14}

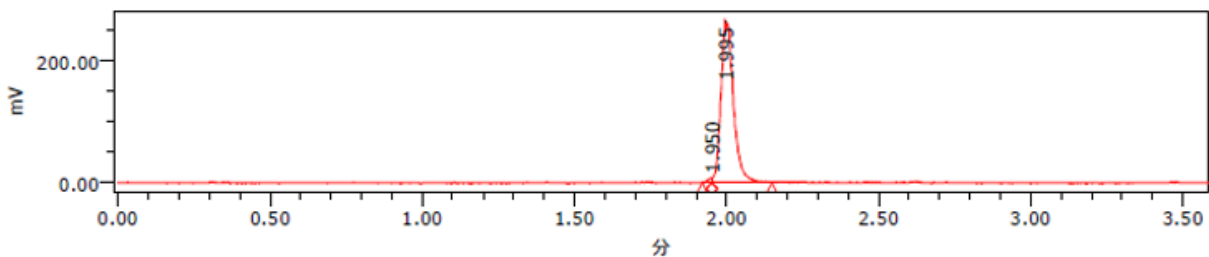

\begin{tabular}{|l|c|r|r|}
\hline & $\begin{array}{c}\text { tR } \\
(\text { 分 })\end{array}$ & $\begin{array}{c}\text { Area } \\
(\mu \mathrm{V} \text { 秒 })\end{array}$ & \%Area \\
\hline 1 & 1.950 & 7784 & 1.02 \\
\hline 2 & 1.995 & 756145 & 98.98 \\
\hline
\end{tabular}




\section{Compound 15}

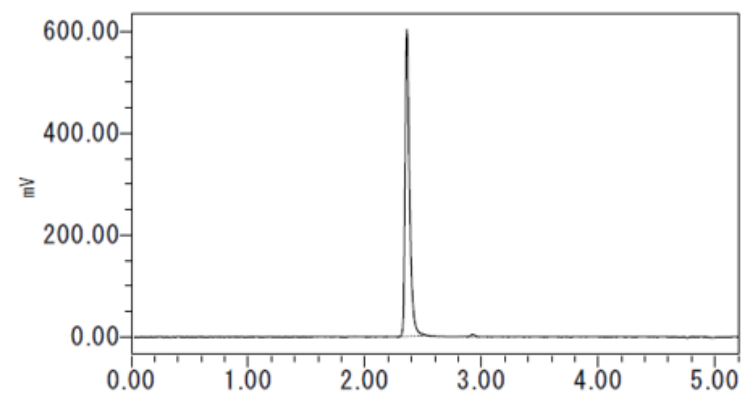

\begin{tabular}{|c|c|c|c|c|}
\hline \multicolumn{5}{|c|}{ Result of Analvs is } \\
\hline & $\begin{array}{l}\text { Retention } \\
\text { Time (m in) }\end{array}$ & $\begin{array}{l}\text { Peak area } \\
(\mu \vee \times \text { sec })\end{array}$ & $\begin{array}{c}\text { D ivisional } \\
\text { m ethod }\end{array}$ & $\%$ of Area \\
\hline 1 & 2.361 & 1621603 & BB & 99.31 \\
\hline 2 & 2.922 & 11290 & BB & 0.69 \\
\hline
\end{tabular}

\section{Compound 16}

1)

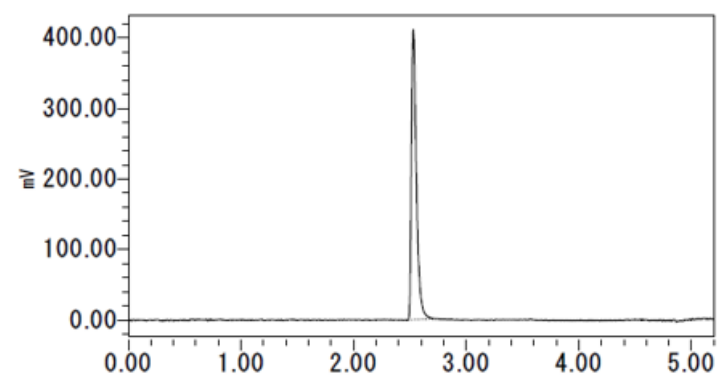

Result of Analvs is
\begin{tabular}{|r|r|r|r|r|}
\hline & $\begin{array}{c}\text { Retention } \\
\text { Tim } \mathrm{e}(\mathrm{m} \text { i })\end{array}$ & $\begin{array}{c}\text { Peak area } \\
(\mu \mathrm{V} \times \mathrm{sec})\end{array}$ & $\begin{array}{c}\text { D is is inal } \\
\text { method }\end{array}$ & \% of A rea \\
\hline 1 & 2.530 & 1275780 & BB & 100.00 \\
\hline
\end{tabular}

2)

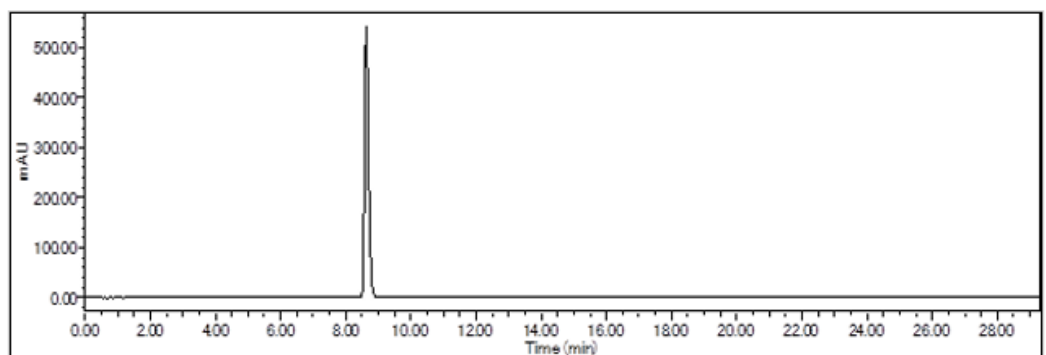

\begin{tabular}{|r|r|r|r|r|}
\hline & \multicolumn{1}{|c|}{ 保持時間 } & \multicolumn{1}{c|}{ 面積 } & \multicolumn{1}{c|}{ \%面積 } & \multicolumn{1}{c|}{ 高さ } \\
\hline 1 & 1.232 & 3373 & 0.07 & 1295 \\
\hline 2 & 1.429 & 519 & 0.01 & 164 \\
\hline 3 & 7.608 & 421 & 0.01 & 59 \\
\hline 4 & 8.629 & 4586898 & 99.89 & 541050 \\
\hline 5 & 14.487 & 316 & 0.01 & 91 \\
\hline 6 & 17.362 & 303 & 0.01 & 151 \\
\hline
\end{tabular}


Instrument:

Column:

Detection

Mobile phase A:

Mobile phase B:

Gradient:

\begin{tabular}{|c|c|}
\hline Time (min) & \%B \\
\hline 0 & 50 \\
\hline 10 & 50 \\
\hline 15 & 90 \\
\hline 20 & 90 \\
\hline 20.1 & 50 \\
\hline 29.3 & 50 \\
\hline
\end{tabular}

Column temp.:

Flow rate:

Sample conc.:

Injection vol.:

UV $215 \mathrm{~nm}$ acid aqueous solution)

Acetonitrile

$35^{\circ} \mathrm{C}$

$1.0 \mathrm{~mL} / \mathrm{min}$

$30 \mu \mathrm{L}$
LC-20A system (detector SPD M20A) (Shimadzu)

SunShell C18, $150 \times 4.6 \mathrm{~mm}$ i.d., $2.6 \mu \mathrm{m}$ (ChromanicTechnologies)

$0.05 \mathrm{~mol} / \mathrm{L}$ sodium perchlorate buffer (adjusted to $\mathrm{pH} 2.5$ with perchloric

$200 \mu \mathrm{g} / \mathrm{mL}$ (Distilled water : acetonitrile $=1: 1$ )

\section{Compound 17}

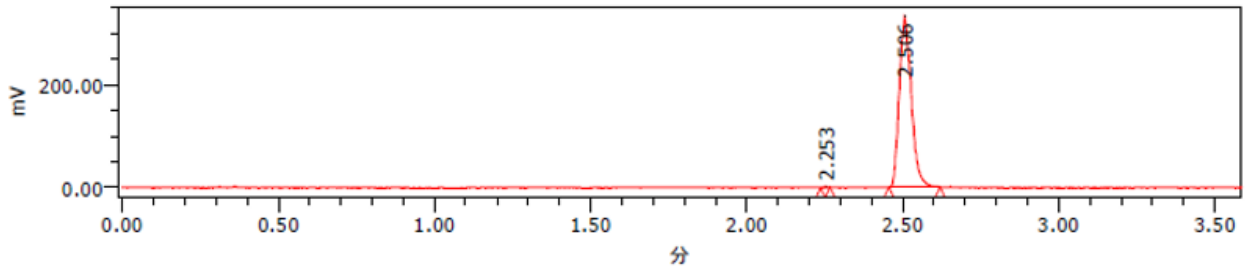

\begin{tabular}{|c|c|r|r|}
\hline & $\begin{array}{c}\text { tR } \\
(\text { (分) }\end{array}$ & $\begin{array}{c}\text { Area } \\
(\mu \mathrm{V} \text { 秒 })\end{array}$ & $\%$ Area \\
\hline 1 & 2.253 & 2018 & 0.23 \\
\hline 2 & 2.506 & 893408 & 99.77 \\
\hline
\end{tabular}

\section{Compound 18}

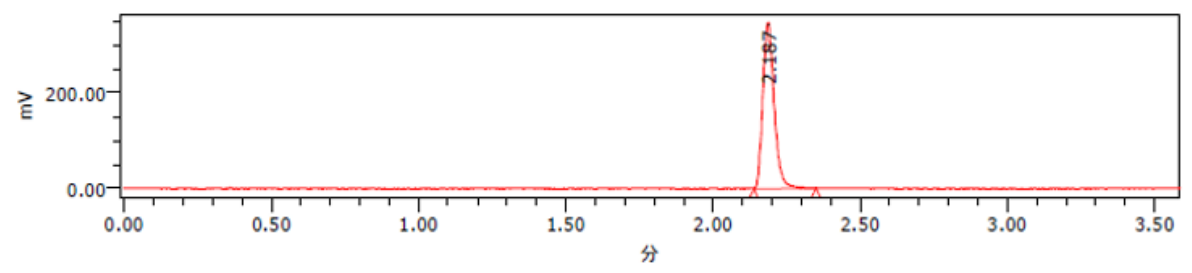

\begin{tabular}{|c|c|c|c|}
\hline & $\begin{array}{c}\text { tR } \\
(\text { 分 })\end{array}$ & $\begin{array}{c}\text { Area } \\
(\mu \mathrm{V} \text { 秒 })\end{array}$ & $\%$ Area \\
\hline 1 & 2.187 & 924168 & 100.00 \\
\hline
\end{tabular}




\section{Chemical synthesis procedures}

General Chemistry Information. All solvents and reagents were obtained from commercial sources and were used as received. Microwave-assisted reactions were carried out in a singlemode reactor, Biotage Initiator 2.0 or 2.5 microwave synthesizer. Yields were not optimized. All reactions were monitored by thin layer chromatography (TLC) analysis on Merck Kieselgel 60 F254 plates or Fuji Silysia NH plates or liquid chromatography-mass spectrometry (LC-MS) analysis. LC-MS analysis was performed on a Shimadzu LC-MS system operating in APCI (+ or -$)$ or ESI ( + or -$)$ ionization mode. Analytes were eluted using a linear gradient with a mobile phase of water/acetonitrile containing $0.05 \%$ TFA or $5 \mathrm{mM}$ ammonium acetate and detected at $220 \mathrm{~nm}$. Column chromatography was carried out on silica gel ((Merck Kieselgel 60, 70-230 mesh, Merck) or (Chromatorex NH-DM 1020, 100-200 mesh, Fuji Silysia Chemical, Ltd.)) or on prepacked Purif-Pack columns (SI or NH, particle size $60 \mu \mathrm{m}$; Fuji Silysia Chemical, Ltd.). Analytical high-performance liquid chromatography (HPLC) was performed using a Corona charged aerosol detector or photodiode array detector with a Capcell Pak C18AQ (3.0 mm ID × $50 \mathrm{~mm}$ L, Shiseido, Japan) or L-column2 ODS (2.0 mm ID $\times 30 \mathrm{~mm} \mathrm{~L}$, CERI, Japan $)$ column at a temperature of $50{ }^{\circ} \mathrm{C}$ and a flow rate of $0.5 \mathrm{~mL} / \mathrm{min}$. Mobile phases $\mathrm{A}$ and $\mathrm{B}$ under neutral conditions were a mixture of $50 \mathrm{mmol} / \mathrm{L}$ ammonium acetate, water, and acetonitrile $(1: 8: 1, \mathrm{v} / \mathrm{v} / \mathrm{v})$ and a mixture of $50 \mathrm{mmol} / \mathrm{L}$ ammonium acetate and acetonitrile $(1: 9, \mathrm{v} / \mathrm{v})$, respectively. The ratio of mobile phase B was increased linearly from $5 \%$ to $95 \%$ over $3 \mathrm{~min}$ and then maintained at $95 \%$ over the next $1 \mathrm{~min}$. Mobile phases $\mathrm{A}$ and $\mathrm{B}$ under acidic conditions were a mixture of $0.2 \%$ formic acid in $10 \mathrm{mmol} / \mathrm{L}$ ammonium formate and $0.2 \%$ formic acid in acetonitrile, respectively. The ratio of mobile phase $\mathrm{B}$ was increased linearly from $14 \%$ to $86 \%$ over $3 \mathrm{~min}$ and then maintained at $86 \%$ over the next $1 \mathrm{~min}$. All final test compounds were purified to $>95 \%$ chemical 
purity as measured by analytical HPLC. Elemental analyses were carried out by Takeda Analytical Laboratories, and all results were within $\pm 0.4 \%$ of the theoretical values. Melting points (mp) were determined on a Büchi B-545 melting point apparatus or a DSC1 system (Mettler-Toledo International Inc., Greifensee, Switzerland). The specific rotatory power was determined by the polarimeter (P-2300 Digital Polarimeter, JASCO corporation). Proton nuclear magnetic resonance $\left({ }^{1} \mathrm{H}\right.$ NMR) spectra were recorded on a Varian Mercury-300 (300 MHz), Varian (400 MHz), Bruker DPX300 (300 MHz), Bruker Avance III (400 MHz), or Bruker AVANCE $\mathrm{II}^{+}(600 \mathrm{MHz})$ instruments. All ${ }^{1} \mathrm{H}$ NMR spectra were consistent with the proposed structures including a mixture of rotamers. All proton shifts are given in parts per million (ppm) downfield from tetramethysilane $(\delta)$ as the internal standard in deuterated solvent, and coupling constants $(J)$ are in hertz $(\mathrm{Hz})$. NMR data are reported as follows: chemical shift, integration, multiplicity (s, singlet; d, doublet; t, triplet; q, quartet; quint, quintet; spt, septet; m, multiplet; dd, doublet of doublets; td, triplet of doublets; ddd, doublet of doublet of doublets; brs, broad singlet; brd, broad doublet; brt, broad triplet; brquin, broad quintet; and brdd, broad doublet of doublets), and coupling constants. Very broad peaks for protons of, for example, hydroxyl and amino groups are not always indicated. 


\section{Synthesis of 3, 4, 5 and $6^{a}$}
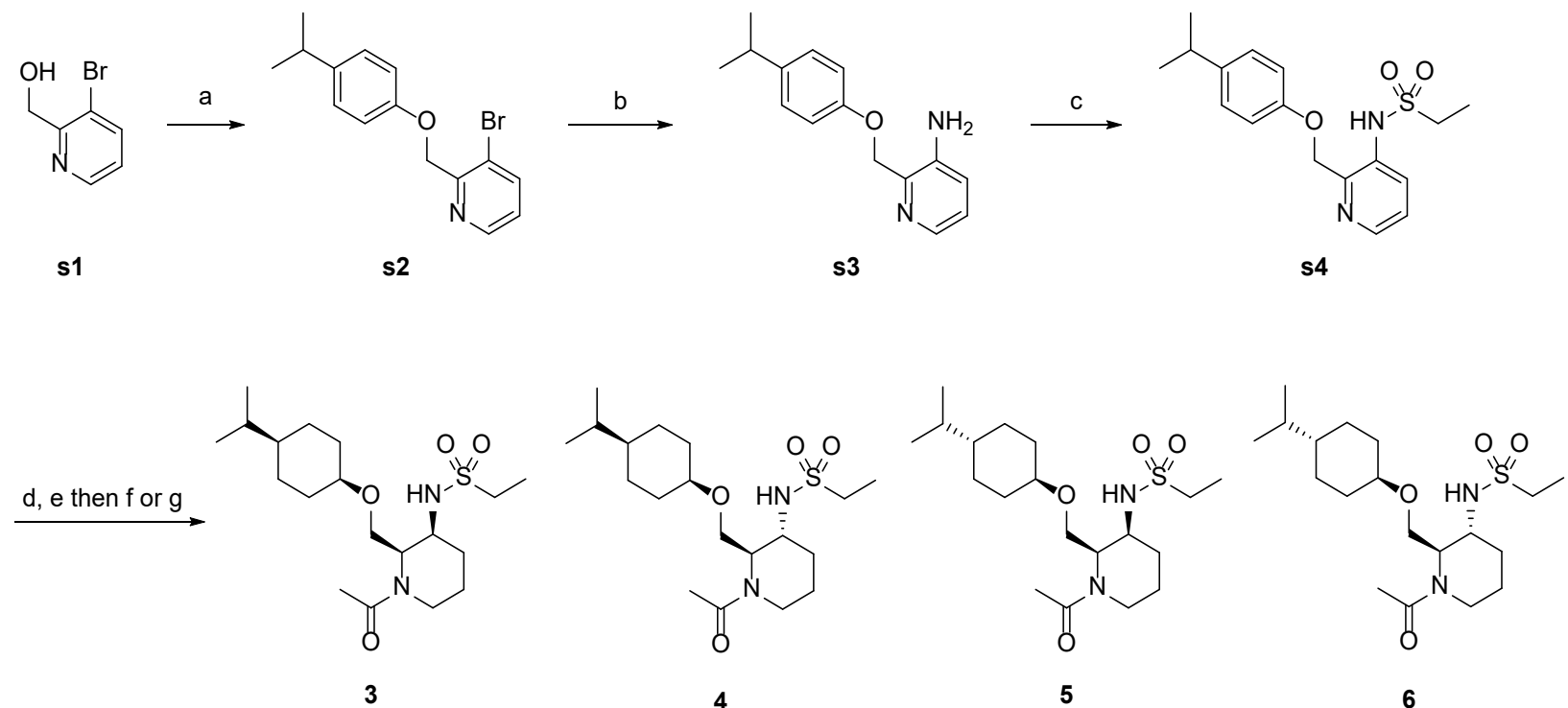

${ }^{a}$ All compounds are racemic mixtures. Reagents and conditions: (a) (1) $\mathrm{SOCl}_{2}, \mathrm{MeCN}$, rt, (2) 4 isopropylphenol, $\mathrm{K}_{2} \mathrm{CO}_{3}$, DMF, rt to $80{ }^{\circ} \mathrm{C}$; (b) (1) diphenylmethanimine, $\mathrm{Pd}_{2}(\mathrm{dba})_{3}$, XPhos, $\mathrm{NaO} t$-Bu, toluene, $80{ }^{\circ} \mathrm{C}$, (2) $2 \mathrm{~N} \mathrm{HCl}$, THF, rt; (c) ethanesulfonyl chloride, pyridine, rt; (d) $\mathrm{H}_{2}$ (44 psi), $\mathrm{PtO}_{2}, \mathrm{AcOH}, \mathrm{EtOH}, 50{ }^{\circ} \mathrm{C}$; (e) $\mathrm{Ac}_{2} \mathrm{O}, \mathrm{Et}_{3} \mathrm{~N}, \mathrm{THF}, \mathrm{rt}$; (f) $\mathrm{H}_{2}(1500 \mathrm{psi}$ ), 10\% Pd/C, $\mathrm{AcOH}$, $100{ }^{\circ} \mathrm{C}$ (for 3 and 5); (g) $\mathrm{H}_{2}$ (190 psi), 5\% Rh/C, EtOH, $170{ }^{\circ} \mathrm{C}$ (for 4 and 6).

\section{3-Bromo-2-((4-isopropylphdenoxy)methyl)pyridine (s2)}

To a mixture of $\mathbf{s 1}(0.13 \mathrm{~g}, 6.7 \mathrm{mmol})$ in $\mathrm{MeCN}(10 \mathrm{~mL})$ was added a mixture of $\mathrm{SOCl}_{2}(0.97$ $\mathrm{mL}, 13.3 \mathrm{mmol})$ in $\mathrm{MeCN}(10 \mathrm{~mL})$ over $20 \mathrm{~min}$ at $\mathrm{rt}$. The mixture was stirred at $\mathrm{rt}$ for $2 \mathrm{~h}$. The mixture was quenched with saturated aqueous $\mathrm{NaHCO}_{3}$ and extracted with EtOAc. The organic layer was separated, washed with saturated aqueous $\mathrm{NaCl}$, dried over anhydrous $\mathrm{Na}_{2} \mathrm{SO}_{4}$, and concentrated in vacuo. To a solution of the residue and 4-isopropylphenol $(0.91 \mathrm{~g}, 6.7 \mathrm{mmol})$ in DMF $(15 \mathrm{~mL})$ was added $\mathrm{K}_{2} \mathrm{CO}_{3}(1.4 \mathrm{~g}, 10 \mathrm{mmol})$ at $\mathrm{rt}$. The mixture was stirred at $80{ }^{\circ} \mathrm{C}$ for $2 \mathrm{~h}$. The mixture was quenched with water and extracted with EtOAc. The organic layer was separated, washed with water and saturated aqueous $\mathrm{NaCl}$, dried over anhydrous $\mathrm{Na}_{2} \mathrm{SO}_{4}$, and 
concentrated in vacuo. The residue was purified by column chromatography (basic silica gel, hexane/EtOAc, 100:0 to $1: 1)$ to give $\mathbf{s} 2(1.3 \mathrm{~g}, 4.3 \mathrm{mmol}, 64 \%)$ as a pale yellow oil. ${ }^{1} \mathrm{H}$ NMR $\left(300 \mathrm{MHz}, \mathrm{CDCl}_{3}\right) \delta 1.21(3 \mathrm{H}, \mathrm{s}), 1.24(3 \mathrm{H}, \mathrm{s}), 2.86(1 \mathrm{H}, \mathrm{spt}, J=6.9 \mathrm{~Hz}), 5.27(2 \mathrm{H}, \mathrm{s})$, 6.94-7.01 (2H, m), 7.11-7.21 (3H, m), $7.91(1 \mathrm{H}, \mathrm{dd}, J=8.1,1.3 \mathrm{~Hz}), 8.58(1 \mathrm{H}, \mathrm{dd}, J=4.5,1.5$ $\mathrm{Hz})$.

\section{2-((4-Isopropylphenoxy)methyl)pyridin-3-amine (s3)}

A mixture of s2 $(2.0 \mathrm{~g}, 6.6 \mathrm{mmol})$, diphenylmethanimine (1.3 mL, $8.0 \mathrm{mmol}), \mathrm{NaOt}-\mathrm{Bu}(0.96 \mathrm{~g}$, $9.9 \mathrm{mmol})$, XPhos (0.63 g, $1.3 \mathrm{mmol})$, and $\mathrm{Pd}_{2}(\mathrm{dba})_{3}(0.61 \mathrm{~g}, 0.66 \mathrm{mmol})$ in toluene $(20 \mathrm{~mL})$ was stirred at $80{ }^{\circ} \mathrm{C}$ for $1 \mathrm{~h}$. The mixture was diluted with water and extracted with EtOAc. The organic layer was separated, washed with saturated aqueous $\mathrm{NaCl}$, dried over anhydrous $\mathrm{Na}_{2} \mathrm{SO}_{4}$, and concentrated in vacuo. The residue was purified by column chromatography (silica gel, hexane/EtOAc, 100:0 to 1:1). A mixture of the residual material and $2 \mathrm{~N} \mathrm{HCl}$ aqueous solution $(5.1 \mathrm{~mL}, 10 \mathrm{mmol})$ in THF $(15 \mathrm{~mL})$ was stirred at $\mathrm{rt}$ for $20 \mathrm{~min}$. The mixture was quenched with saturated aqueous $\mathrm{NaHCO}_{3}$ and extracted with EtOAc. The organic layer was separated, washed with saturated aqueous $\mathrm{NaCl}$, dried over anhydrous $\mathrm{Na}_{2} \mathrm{SO}_{4}$, and concentrated in vacuo. The residue was purified by column chromatography (basic silica gel, hexane/EtOAc, 100:0 to 7:3) to give s3 (0.90 g, $3.7 \mathrm{mmol}, 74 \%)$ as a pale yellow solid. ${ }^{1} \mathrm{H} \mathrm{NMR}\left(300 \mathrm{MHz}, \mathrm{CDCl}_{3}\right) \delta 1.20(3 \mathrm{H}$, s), $1.22(3 \mathrm{H}, \mathrm{s}), 2.85(1 \mathrm{H}, \mathrm{spt}, J=6.9 \mathrm{~Hz}), 4.21(2 \mathrm{H}, \mathrm{brs}), 5.24(2 \mathrm{H}, \mathrm{s}), 6.93-7.01(3 \mathrm{H}, \mathrm{m})$, 7.03-7.10 (1H, m), 7.10-7.17 (2H, m), $8.00(1 \mathrm{H}, \mathrm{dd}, J=4.5,1.5 \mathrm{~Hz})$.

\section{$N$-(2-((4-Isopropylphenoxy)methyl)pyridin-3-yl)ethanesulfonamide (s4)}

A mixture of $\mathbf{s} 3(1.2 \mathrm{~g}, 5.0 \mathrm{mmol})$ and ethanesulfonyl chloride $(0.71 \mathrm{~mL}, 7.5 \mathrm{mmol})$ in pyridine $(15 \mathrm{~mL})$ was stirred at rt overnight. The mixture was concentrated in vacuo, diluted with water, 
and extracted with EtOAc. The organic layer was separated, washed with water and saturated aqueous $\mathrm{NaCl}$, dried over anhydrous $\mathrm{Na}_{2} \mathrm{SO}_{4}$, and concentrated in vacuo. The residue was purified by column chromatography (silica gel, hexane/EtOAc, 19:1 to 1:1). The residual orange oil was treated with activated charcoal in $\mathrm{MeOH}$ to give $\mathbf{s 4}(1.4 \mathrm{~g}, 4.2 \mathrm{mmol}, 83 \%)$ as a pale yellow oil. ${ }^{1} \mathrm{H}$ NMR $\left(300 \mathrm{MHz}, \mathrm{CDCl}_{3}\right) \delta 1.20(3 \mathrm{H}, \mathrm{s}), 1.22(3 \mathrm{H}, \mathrm{s}), 1.34(3 \mathrm{H}, \mathrm{t}, J=7.4 \mathrm{~Hz}), 2.85$ $(1 \mathrm{H}, \mathrm{spt}, J=7.0 \mathrm{~Hz}), 3.12(2 \mathrm{H}, \mathrm{q}, J=7.6 \mathrm{~Hz}), 5.35(2 \mathrm{H}, \mathrm{s}), 6.92-6.98(2 \mathrm{H}, \mathrm{m}), 7.11-7.19(2 \mathrm{H}$, m), $7.27(1 \mathrm{H}, \mathrm{dd}, J=8.5,4.7 \mathrm{~Hz}), 7.85(1 \mathrm{H}, \mathrm{brs}), 7.95(1 \mathrm{H}, \mathrm{dd}, J=8.3,1.5 \mathrm{~Hz}), 8.34(1 \mathrm{H}, \mathrm{dd}, J=$ $4.5,1.5 \mathrm{~Hz})$.

\section{N-(cis-1-Acetyl-2-(((cis-4-isopropylcyclohexyl)oxy)methyl)piperidin-3-yl)ethanesulfonamide} (3)

A mixture of s4 $(1.4 \mathrm{~g}, 4.2 \mathrm{mmol})$ and $\mathrm{PtO}_{2}(47 \mathrm{mg}, 0.21 \mathrm{mmol})$ in $\mathrm{EtOH}(30 \mathrm{~mL})$ and $\mathrm{AcOH}$ $(20 \mathrm{~mL})$ was hydrogenated under 40 psi at $50{ }^{\circ} \mathrm{C}$ overnight. The catalyst was removed by filtration and the filtrate was concentrated in vacuo. The residue was purified by column chromatography (basic silica gel, hexane/EtOAc, $7: 3$ to $0: 100)$ to give $N$-(cis-2-((4isopropylphenoxy)methyl)piperidin-3-yl)ethanesulfonamide (0.54 g, $1.6 \mathrm{mmol}, 38 \%)$ as colorless oil. The mixture of $\mathrm{N}$-(cis-2-((4-isopropylphenoxy)methyl)piperidin-3-yl)ethanesulfonamide (0.54 g, $1.6 \mathrm{mmol}), \mathrm{Et}_{3} \mathrm{~N}(0.66 \mathrm{~mL}, 4.7 \mathrm{mmol})$ and $\mathrm{Ac}_{2} \mathrm{O}(0.22 \mathrm{~mL}, 2.4 \mathrm{mmol})$ in $\mathrm{THF}(7 \mathrm{~mL})$ was stirred at rt overnight. The mixture was quenched with saturated aqueous $\mathrm{NaHCO}_{3}$ and extracted with EtOAc. The organic layer was separated, washed with saturated aqueous $\mathrm{NaCl}$, dried over anhydrous $\mathrm{Na}_{2} \mathrm{SO}_{4}$, and concentrated in vacuo. The residue was crystallized from EtOAc-hexane to give $\quad N$-(cis-1-acetyl-2-((4-isopropylphenoxy)methyl)piperidin-3yl)ethanesulfonamide $\quad(0.52 \mathrm{~g}, \quad 1.4 \mathrm{mmol}, \quad 87 \%)$. The mixture of $N$-(cis-2-((4isopropylphenoxy)methyl)piperidin-3-yl)ethanesulfonamide $(0.15 \mathrm{~g}, 0.39 \mathrm{mmol})$ and $10 \% \mathrm{Pd}-\mathrm{C}$ 
(containing 50\% water, $75 \mathrm{mg}$ ) in $\mathrm{AcOH}(15 \mathrm{~mL})$ was hydrogenated under $1500 \mathrm{psi}$ at $100{ }^{\circ} \mathrm{C}$ for $5 \mathrm{~h}$. The catalyst was removed by filtration and the filtrate was concentrated in vacuo. The residue was diluted with EtOAc and the solution was washed with saturated aqueous $\mathrm{NaHCO}_{3}$, dried over anhydrous $\mathrm{Na}_{2} \mathrm{SO}_{4}$, and concentrated in vacuo. The residue was purified by a preparative HPLC purification (column, L-Column2 ODS $20 \mathrm{~mm}$ ID $\times 150 \mathrm{~mm} \mathrm{~L}$; mobile phase A, (10 mM NH $\left.4 \mathrm{HCO}_{3}\right) \mathrm{H}_{2} \mathrm{O} / \mathrm{MeCN}, 900 / 100$; mobile phase $\mathrm{B},\left(10 \mathrm{mM} \mathrm{NH}_{4} \mathrm{HCO}_{3}\right) \mathrm{H}_{2} \mathrm{O} / \mathrm{MeCN}$, 100/900; flow rate, $20 \mathrm{~mL} / \mathrm{min})$ to give $3(25 \mathrm{mg}, 0.064 \mathrm{mmol}, 19 \%)$ as oil. ${ }^{1} \mathrm{H} \mathrm{NMR}(600 \mathrm{MHz}$, DMSO- $d_{6}$, rotamer ratio $\left.=75: 25\right) \delta 0.79-0.84(6 \mathrm{H}, \mathrm{m}), 1.00-1.08(1 \mathrm{H}, \mathrm{m}), 1.11-1.42(10.75 \mathrm{H}$, m), 1.45-1.57 (1H, m), 1.60-1.73 (2.25H, m), 1.74-1.87 (2H, m), $1.98(0.75 \mathrm{H}, \mathrm{s}), 2.00(2.25 \mathrm{H}$, s), $2.50-2.56(0.75 \mathrm{H}, \mathrm{m}), 2.97-3.16(2.25 \mathrm{H}, \mathrm{m}), 3.21(0.25 \mathrm{H}, \mathrm{dq}, J=11.7,5.9 \mathrm{~Hz}), 3.34-3.40$ $(0.75 \mathrm{H}, \mathrm{m}), 3.46-3.51(1 \mathrm{H}, \mathrm{m}), 3.55-3.62(1.25 \mathrm{H}, \mathrm{m}), 3.63-3.69(1 \mathrm{H}, \mathrm{m}), 4.10-4.15(0.75 \mathrm{H}, \mathrm{m})$, $4.25(0.75 \mathrm{H}$, brdd, $J=13.4,3.9 \mathrm{~Hz}), 4.80-4.86(0.25 \mathrm{H}, \mathrm{m}), 7.12(0.25 \mathrm{H}$, brd, $J=7.4 \mathrm{~Hz}), 7.31$ $(0.75 \mathrm{H}$, brd, $J=6.2 \mathrm{~Hz}) .{ }^{13} \mathrm{C}$ NMR $\left(151 \mathrm{MHz}, \mathrm{DMSO}-d_{6}\right.$, the minor rotamer's signals are marked with an asterisk) $\delta 8.10,19.41,19.49,19.54^{*}, 21.43,21.76^{*}, 23.05,23.15,23.28^{*}, 23.32 *, 23.90$, $24.90^{*}, 26.14,26.76^{*}, 28.78,28.85^{*}, 29.37^{*}, 29.75,31.93 *, 32.00,34.12,40.68^{*}, 42.63,42.66^{*}$, $45.55,45.91^{*}, 50.64^{*}, 51.05^{*}, 51.43,58.00,61.09,62.44^{*}, 72.53^{*}, 72.78,168.31^{*}, 168.99 . \mathrm{MS}$ (ESI/APCI) mass calculated for $[\mathrm{M}+\mathrm{H}]^{+}\left(\mathrm{C}_{19} \mathrm{H}_{37} \mathrm{~N}_{2} \mathrm{O}_{4} \mathrm{~S}\right)$ requires $\mathrm{m} / \mathrm{z} 388.6$, found $\mathrm{m} / \mathrm{z} 389.3$.

\section{N-(trans-1-Acetyl-2-(((cis-4-isopropylcyclohexyl)oxy)methyl)piperidin-3-}

\section{yl)ethanesulfonamide (4)}

A mixture of $\mathbf{s} 4(1.4 \mathrm{~g}, 4.2 \mathrm{mmol})$ and $\mathrm{PtO}_{2}(47 \mathrm{mg}, 0.21 \mathrm{mmol})$ in $\mathrm{EtOH}(30 \mathrm{~mL})$ and $\mathrm{AcOH}$ $(20 \mathrm{~mL})$ was hydrogenated under $44 \mathrm{psi}$ at $50{ }^{\circ} \mathrm{C}$ overnight. The catalyst was removed by

filtration and the filtrate was concentrated in vacuo. The residue was purified by column chromatography (basic silica gel, hexane/EtOAc, 7:3 to 0:100) to give $N$-(trans-2-((4- 
isopropylphenoxy)methyl)piperidin-3-yl)ethanesulfonamide $(0.19 \mathrm{~g}, 0.56 \mathrm{mmol}, 13 \%)$. The mixture of $N$-(trans-2-((4-isopropylphenoxy)methyl)piperidin-3-yl)ethanesulfonamide $(0.19 \mathrm{~g}$, $0.56 \mathrm{mmol}), \mathrm{Et}_{3} \mathrm{~N}(0.23 \mathrm{~mL}, 1.7 \mathrm{mmol})$ and $\mathrm{Ac}_{2} \mathrm{O}(0.11 \mathrm{~mL}, 1.1 \mathrm{mmol})$ in $\mathrm{THF}(5 \mathrm{~mL})$ was stirred at $\mathrm{rt}$ for $2 \mathrm{~h}$. The mixture was quenched with saturated aqueous $\mathrm{NaHCO}_{3}$ and extracted with EtOAc. The organic layer was separated, washed with saturated aqueous $\mathrm{NaCl}$, dried over anhydrous $\mathrm{Na}_{2} \mathrm{SO}_{4}$, and concentrated in vacuo. The residue was purified by column chromatography (silica gel, hexane/EtOAc, 1:1 to $0: 100$ ). The residue was crystallized from EtOAc-hexane to give $N$-(trans-1-acetyl-2-((4-isopropylphenoxy)methyl)piperidin-3yl)ethanesulfonamide $(0.20 \mathrm{~g}, 0.51 \mathrm{mmol}, 92 \%)$. The mixture of $N$-(trans-1-acetyl-2-((4isopropylphenoxy)methyl)piperidin-3-yl)ethanesulfonamide $(0.20 \mathrm{~g}, 0.51 \mathrm{mmol})$ and 5\% Rh-C (containing $50 \%$ water, $0.11 \mathrm{~g}$ ) in $\mathrm{EtOH}(10 \mathrm{~mL})$ was hydrogenated under 190 psi at $170{ }^{\circ} \mathrm{C}$ for 5 h. The catalyst was removed by filtration and the filtrate was concentrated in vacuo. The residue was purified by a preparative HPLC purification (column, L-Column2 ODS $20 \mathrm{~mm}$ ID $\times 150 \mathrm{~mm}$ L; mobile phase A, (10 mM NH $\left.\mathrm{mHCO}_{3}\right) \mathrm{H}_{2} \mathrm{O} / \mathrm{MeCN}, 900 / 100$; mobile phase $\mathrm{B}$, (10 mM $\left.\mathrm{NH}_{4} \mathrm{HCO}_{3}\right) \mathrm{H}_{2} \mathrm{O} / \mathrm{MeCN}, 100 / 900$; flow rate, $\left.20 \mathrm{~mL} / \mathrm{min}\right)$ to give 4 (17 mg, $0.044 \mathrm{mmol}, 9.7 \%$ ) as oil. ${ }^{1} \mathrm{H}$ NMR $\left(600 \mathrm{MHz}, \mathrm{DMSO}-d_{6}\right.$, rotamer ratio $\left.=67: 33\right) \delta 0.81(4.02 \mathrm{H}, \mathrm{d}, J=6.6 \mathrm{~Hz}), 0.83$ $(1.98 \mathrm{H}, \mathrm{d}, J=7.0 \mathrm{~Hz}), 1.00-1.09(1 \mathrm{H}, \mathrm{m}), 1.13-1.43(11 \mathrm{H}, \mathrm{m}), 1.54-1.61(1 \mathrm{H}, \mathrm{m}), 1.62-1.71$ $(0.67 \mathrm{H}, \mathrm{m}), 1.74(0.67 \mathrm{H}, \mathrm{tt}, J=13.2,3.3 \mathrm{~Hz}), 1.77-1.87(2.66 \mathrm{H}, \mathrm{m}), 1.98(0.99 \mathrm{H}, \mathrm{s}), 2.02(2.01 \mathrm{H}$, s), $2.55(0.67 \mathrm{H}, \mathrm{td}, J=13.0,2.8 \mathrm{~Hz}), 2.95(0.66 \mathrm{H}, \mathrm{q}, J=7.2 \mathrm{~Hz}), 3.02-3.08(1.67 \mathrm{H}, \mathrm{m}), 3.25$ $(0.33 \mathrm{H}, \mathrm{dd}, J=9.5,5.5 \mathrm{~Hz}), 3.45(0.67 \mathrm{H}, \mathrm{dd}, J=9.7,5.0 \mathrm{~Hz}), 3.47-3.53(2 \mathrm{H}, \mathrm{m}), 3.56-3.63(1 \mathrm{H}$, m), $3.66(0.33 \mathrm{H}$, brd, $J=7.7 \mathrm{~Hz}), 4.02-4.07(0.67 \mathrm{H}, \mathrm{m}), 4.31(0.67 \mathrm{H}$, brdd, $J=13.4,2.8 \mathrm{~Hz})$, $4.60(0.33 \mathrm{H}$, brt, $J=6.6 \mathrm{~Hz}), 7.33-7.38(1 \mathrm{H}, \mathrm{m}) .{ }^{13} \mathrm{C}$ NMR $\left(151 \mathrm{MHz}, \mathrm{DMSO}-d_{6}\right.$, the minor rotamer's signals are marked with an asterisk) $\delta 8.03,8.07^{*}, 18.77,19.04^{*}, 19.40^{*}, 19.48,21.43$, $21.87^{*}, 23.07,23.15,23.27^{*}, 25.13,25.26^{*}, 28.90^{*}, 28.94,29.48^{*}, 29.51,31.94 *, 31.97,34.85$ 
$41.73^{*}, 42.59,45.68,46.66^{*}, 47.35^{*}, 47.95,52.57 *, 59.12,64.44,72.51^{*}, 72.67,169.14^{*}$, 169.58. MS (ESI/APCI) mass calculated for $[\mathrm{M}+\mathrm{H}]^{+}\left(\mathrm{C}_{19} \mathrm{H}_{37} \mathrm{~N}_{2} \mathrm{O}_{4} \mathrm{~S}\right)$ requires $\mathrm{m} / \mathrm{z} 388.6$, found $\mathrm{m} / \mathrm{z} 389.4$.

\section{$N$-(cis-1-Acetyl-2-(((trans-4-isopropylcyclohexyl)oxy)methyl)piperidin-3-}

\section{yl)ethanesulfonamide (5)}

A mixture of s4 $(1.4 \mathrm{~g}, 4.2 \mathrm{mmol})$ and $\mathrm{PtO}_{2}(47 \mathrm{mg}, 0.21 \mathrm{mmol})$ in $\mathrm{EtOH}(30 \mathrm{~mL})$ and $\mathrm{AcOH}$ $(20 \mathrm{~mL})$ was hydrogenated under $44 \mathrm{psi}$ at $50{ }^{\circ} \mathrm{C}$ overnight. The catalyst was removed by filtration and the filtrate was concentrated in vacuo. The residue was purified by column chromatography (basic silica gel, hexane/EtOAc, $7: 3$ to $0: 100)$ to give $N$-(cis-2-((4isopropylphenoxy)methyl)piperidin-3-yl)ethanesulfonamide (0.54 g, $1.6 \mathrm{mmol}, 38 \%)$. The mixture of $N$-(cis-2-((4-isopropylphenoxy)methyl)piperidin-3-yl)ethanesulfonamide $(0.54 \mathrm{~g}, 1.6$ mmol), $\mathrm{Et}_{3} \mathrm{~N}(0.66 \mathrm{~mL}, 4.7 \mathrm{mmol})$, and $\mathrm{Ac}_{2} \mathrm{O}(0.22 \mathrm{~mL}, 2.4 \mathrm{mmol})$ in THF $(7 \mathrm{~mL})$ was stirred at rt overnight. The mixture was quenched with saturated aqueous $\mathrm{NaHCO}_{3}$ and extracted with EtOAc. The organic layer was separated, washed with saturated aqueous $\mathrm{NaCl}$, dried over anhydrous $\mathrm{Na}_{2} \mathrm{SO}_{4}$, and concentrated in vacuo. The residue was crystallized from EtOAc-hexane to give $N$-(cis-1-acetyl-2-((4-isopropylphenoxy)methyl)piperidin-3-yl)ethanesulfonamide (0.52 g, $1.4 \mathrm{mmol}, \quad 87 \%)$. The mixture of $\quad \mathrm{N}$-(cis-2-((4-isopropylphenoxy)methyl)piperidin-3yl)ethanesulfonamide $(0.15 \mathrm{~g}, 0.39 \mathrm{mmol})$ and $10 \%$ Pd-C (containing $50 \%$ water, $75 \mathrm{mg})$ in AcOH $(15 \mathrm{~mL})$ was hydrogenated under $1500 \mathrm{psi}$ at $100{ }^{\circ} \mathrm{C}$ for $5 \mathrm{~h}$. The catalyst was removed by filtration and the filtrate was concentrated in vacuo. The residue was diluted with EtOAc and the solution was washed with saturated aqueous $\mathrm{NaHCO}_{3}$, dried over anhydrous $\mathrm{Na}_{2} \mathrm{SO}_{4}$, and concentrated in vacuo. The residue was purified by a preparative HPLC purification (column, LColumn2 ODS $20 \mathrm{~mm}$ ID $\times 150 \mathrm{~mm} \mathrm{~L}$; mobile phase A, $\left(10 \mathrm{mM} \mathrm{NH} \mathrm{H}_{4} \mathrm{HCO}_{3}\right) \mathrm{H}_{2} \mathrm{O} / \mathrm{MeCN}$, 
900/100; mobile phase $\mathrm{B},\left(10 \mathrm{mM} \mathrm{NH}_{4} \mathrm{HCO}_{3}\right) \mathrm{H}_{2} \mathrm{O} / \mathrm{MeCN}, 100 / 900$; flow rate, $\left.20 \mathrm{~mL} / \mathrm{min}\right)$ to give $5(62 \mathrm{mg}, 0.16 \mathrm{mmol}, 47 \%)$ as oil. ${ }^{1} \mathrm{H}$ NMR (600 MHz, DMSO- $d_{6}$, rotamer ratio $\left.=7: 3\right) \delta$ $0.83(6 \mathrm{H}, \mathrm{d}, J=6.6 \mathrm{~Hz}), 0.89-1.01(3 \mathrm{H}, \mathrm{m}), 1.01-1.12(2 \mathrm{H}, \mathrm{m}), 1.16-1.21(3 \mathrm{H}, \mathrm{m}), 1.29-1.43$ (1.7H, m), 1.44-1.55 (1.3H, m), 1.59-1.70 (4.3H, m), 1.90-2.01 (5H, m), 2.50-2.55 (0.7H, m), 2.95-3.21 (3.6H, m), 3.31-3.37 $(0.7 \mathrm{H}, \mathrm{m}), 3.55(0.3 \mathrm{H}$, brdd, $J=13.6,3.7 \mathrm{~Hz}), 3.63-3.74(2 \mathrm{H}$, m), 4.04-4.10 (0.7H, m), $4.24(0.7 \mathrm{H}$, brdd, $J=13.6,4.0 \mathrm{~Hz}), 4.80-4.85(0.3 \mathrm{H}, \mathrm{m}), 7.13(0.3 \mathrm{H}, \mathrm{d}$, $J=7.3 \mathrm{~Hz}), 7.31(0.7 \mathrm{H}, \mathrm{d}, J=7.3 \mathrm{~Hz}) \cdot{ }^{13} \mathrm{C}$ NMR $\left(151 \mathrm{MHz}, \mathrm{DMSO}-d_{6}\right.$, the minor rotamer's signals are marked with an asterisk) $\delta 8.11,19.73,19.74,21.42,21.73 *, 23.93,24.92 *, 26.13$, $26.67 *, 27.09,27.12,27.19 *, 27.24 *, 31.72 *, 31.74,31.78^{*}, 31.79,32.01 *, 32.04,34.17,40.44 *$, $42.69,42.76^{*}, 45.56,46.00^{*}, 50.77^{*}, 50.93^{*}, 51.47,58.19,61.35,62.11^{*}, 77.36^{*}, 78.02$, 168.35*, 168.98. MS (ESI/APCI) mass calculated for $[\mathrm{M}+\mathrm{H}]^{+}\left(\mathrm{C}_{19} \mathrm{H}_{37} \mathrm{~N}_{2} \mathrm{O}_{4} \mathrm{~S}\right)$ requires $\mathrm{m} / \mathrm{z}$ 388.6, found $\mathrm{m} / \mathrm{z} 389.4$.

\section{$N$-(trans-1-Acetyl-2-(((trans-4-isopropylcyclohexyl)oxy)methyl)piperidin-3-}

\section{yl)ethanesulfonamide (6)}

A mixture of s4 $(1.4 \mathrm{~g}, 4.2 \mathrm{mmol})$ and $\mathrm{PtO}_{2}(47 \mathrm{mg}, 0.21 \mathrm{mmol})$ in $\mathrm{EtOH}(30 \mathrm{~mL})$ and $\mathrm{AcOH}$ $(20 \mathrm{~mL})$ was hydrogenated under $44 \mathrm{psi}$ at $50{ }^{\circ} \mathrm{C}$ overnight. The catalyst was removed by filtration and the filtrate was concentrated in vacuo. The residue was purified by column chromatography (basic silica gel, hexane/EtOAc, 7:3 to 0:100) to give $N$-(trans-2-((4isopropylphenoxy)methyl)piperidin-3-yl)ethanesulfonamide (0.19 g, $0.56 \mathrm{mmol}, 13 \%)$. The mixture of $N$-(trans-2-((4-isopropylphenoxy)methyl)piperidin-3-yl)ethanesulfonamide (0.19 mg, $0.56 \mathrm{mmol}), \mathrm{Et}_{3} \mathrm{~N}(0.23 \mathrm{~mL}, 1.67 \mathrm{mmol})$, and $\mathrm{Ac}_{2} \mathrm{O}(0.11 \mathrm{~mL}, 1.12 \mathrm{mmol})$ in THF $(5 \mathrm{~mL})$ was stirred at $\mathrm{rt}$ for $2 \mathrm{~h}$. The mixture was quenched with saturated aqueous $\mathrm{NaHCO}_{3}$ and extracted with EtOAc. The organic layer was separated, washed with saturated aqueous $\mathrm{NaCl}$, dried over 
anhydrous $\mathrm{Na}_{2} \mathrm{SO}_{4}$, and concentrated in vacuo. The residue was purified by column chromatography (silica gel, hexane/EtOAc, 1:1 to 0:100). The residue was crystallized from EtOAc-hexane to give $\quad N$-(trans-1-acetyl-2-((4-isopropylphenoxy)methyl)piperidin-3yl)ethanesulfonamide $(0.20 \mathrm{~g}, 0.51 \mathrm{mmol}, 92 \%)$. The mixture of $N$-(trans-1-acetyl-2-((4isopropylphenoxy)methyl)piperidin-3-yl)ethanesulfonamide $(0.20 \mathrm{~g}, 0.51 \mathrm{mmol})$ and $5 \% \mathrm{Rh}-\mathrm{C}$ (containing 50\% water, $0.11 \mathrm{~g})$ in $\mathrm{EtOH}(10 \mathrm{~mL})$ was hydrogenated under 190 psi at $170{ }^{\circ} \mathrm{C}$ for 5 h. The catalyst was removed by filtration and the filtrate was concentrated in vacuo. The residue was purified by a preparative HPLC purification (column, L-Column2 ODS $20 \mathrm{~mm}$ ID $\times 150 \mathrm{~mm}$ $\mathrm{L}$; mobile phase A, (10 mM NH $\left.\mathrm{NHCO}_{3}\right) \mathrm{H}_{2} \mathrm{O} / \mathrm{MeCN}, 900 / 100$; mobile phase $\mathrm{B}$, (10 mM $\left.\mathrm{NH}_{4} \mathrm{HCO}_{3}\right) \mathrm{H}_{2} \mathrm{O} / \mathrm{MeCN}, 100 / 900$; flow rate, $\left.20 \mathrm{~mL} / \mathrm{min}\right)$ to give 6 (72 $\left.\mathrm{mg}, 0.19 \mathrm{mmol}, 41 \%\right)$ as oil. ${ }^{1} \mathrm{H}$ NMR $\left(600 \mathrm{MHz}, \mathrm{DMSO}-d_{6}\right.$, rotamer ratio $\left.=65: 35\right) \delta 0.82(6 \mathrm{H}, \mathrm{d}, J=6.6 \mathrm{~Hz}), 0.90-1.00$ $(3 \mathrm{H}, \mathrm{m}), 1.00-1.11(2 \mathrm{H}, \mathrm{m}), 1.19(3 \mathrm{H}, \mathrm{t}, J=7.3 \mathrm{~Hz}), 1.34-1.43(2 \mathrm{H}, \mathrm{m}), 1.52-1.59(1 \mathrm{H}, \mathrm{m})$, $1.61-1.69(2.65 \mathrm{H}, \mathrm{m}), 1.73(0.65 \mathrm{H}, \mathrm{tt}, J=13.4,3.7 \mathrm{~Hz}), 1.78-1.84(0.7 \mathrm{H}, \mathrm{m}), 1.91-2.03(5 \mathrm{H}, \mathrm{m})$, $2.54(0.65 \mathrm{H}, \mathrm{td}, J=12.9,2.4 \mathrm{~Hz}), 2.91-2.98(0.7 \mathrm{H}, \mathrm{m}), 2.98-3.08(1.65 \mathrm{H}, \mathrm{m}), 3.10-3.17(1 \mathrm{H}$, $\mathrm{m}), 3.30-3.33(0.35 \mathrm{H}, \mathrm{m}), 3.46-3.51(0.65 \mathrm{H}, \mathrm{m}), 3.51-3.66(2.35 \mathrm{H}, \mathrm{m}), 3.99(0.65 \mathrm{H}, \mathrm{brt}, J=6.4$ $\mathrm{Hz}), 4.29(0.65 \mathrm{H}$, brdd, $J=13.2,1.8 \mathrm{~Hz}), 4.57(0.35 \mathrm{H}$, brt, $J=6.4 \mathrm{~Hz}), 7.33-7.38(1 \mathrm{H}, \mathrm{m}) .{ }^{13} \mathrm{C}$ NMR (151 MHz, DMSO-d6, the minor rotamer's signals are marked with an asterisk) $\delta 8.04$, $8.08^{*}, 18.76,18.99^{*}, 19.72,21.42,21.87^{*}, 24.98,25.02 *, 27.12,27.18^{*}, 27.20^{*}, 31.74,31.76^{*}$, $31.79^{*}, 31.86,31.91,32.02^{*}, 34.93,41.57^{*}, 42.66,42.68^{*}, 45.71,46.74^{*}, 47.18^{*}, 47.89,52.52^{*}$, $59.19,64.47^{*}, 64.70,77.67^{*}, 77.99,169.15^{*}, 169.54$. MS (ESI/APCI) mass calculated for [M + $\mathrm{H}]^{+}\left(\mathrm{C}_{19} \mathrm{H}_{37} \mathrm{~N}_{2} \mathrm{O}_{4} \mathrm{~S}\right)$ requires $\mathrm{m} / \mathrm{z} 388.6$, found $\mathrm{m} / \mathrm{z} 389.4$. 

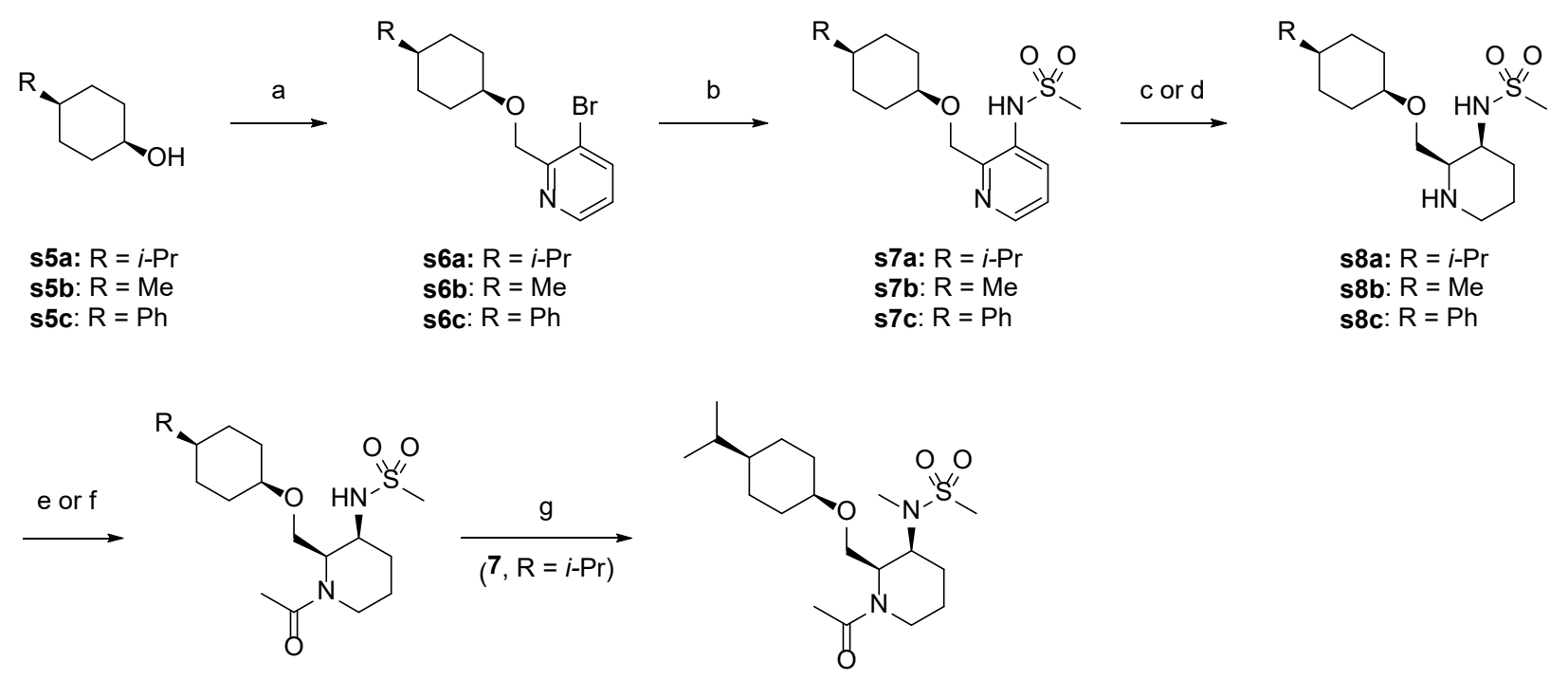

7: $\mathrm{R}=i-\mathrm{Pr}$ 12: $\mathrm{R}=\mathrm{Me}$ 13: $\mathrm{R}=\mathrm{Ph}$

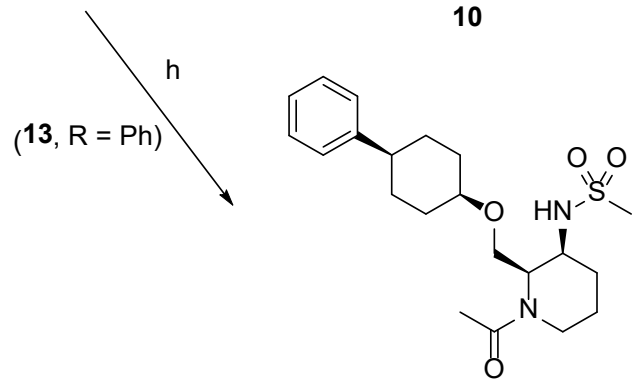

$13 a$

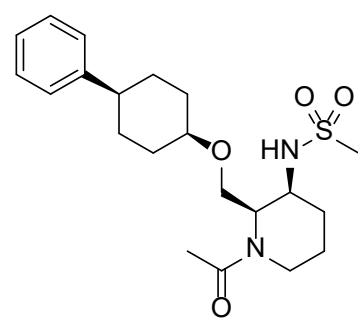

13b

${ }^{a}$ Reagents and conditions: (a) bromo-2-(bromomethyl)pyridine, $60 \% \mathrm{NaH}$ in oil, $\mathrm{THF}, 0{ }^{\circ} \mathrm{C}-\mathrm{rt}$; (b) methanesulfonamide, $\mathrm{Pd}_{2}(\mathrm{dba})_{3}, t$-BuXPhos, $\mathrm{Cs}_{2} \mathrm{CO}_{3}, \mathrm{THF}, 120{ }^{\circ} \mathrm{C}$ (microwave); (c) $\mathrm{H}_{2}(87$ psi), $\mathrm{PtO}_{2}, \mathrm{AcOH}, \mathrm{MeOH}, 50{ }^{\circ} \mathrm{C}$ (for s8a and s8b); (d) $\mathrm{H}_{2}$ (balloon), $\mathrm{PtO}_{2}, \mathrm{AcOH}, \mathrm{MeOH}, \mathrm{rt}$ (for s8c); (e) AcCl, DIEA, DMA, rt (for 7); (f) $\mathrm{Ac}_{2} \mathrm{O}$, Et $\mathrm{t}_{3} \mathrm{~N}, \mathrm{THF}, 0{ }^{\circ} \mathrm{C}-\mathrm{rt}$ (for 12 and 13); (g) 7, 60\% $\mathrm{NaH}$ in oil, MeI, DMA, $0{ }^{\circ} \mathrm{C}$; (h) $\mathbf{1 3}$, chiral column separation.

\section{3-Bromo-2-(((cis-4-isopropylcyclohexyl)oxy)methyl)pyridine (s6a)}

To a suspension of $60 \% \mathrm{NaH}$ in oil $(7.0 \mathrm{~g}, 0.18 \mathrm{~mol})$ in THF $(80 \mathrm{~mL})$ was added $\mathbf{s 5 a}(20 \mathrm{~g}, 0.14$ mol) at rt. The mixture was stirred at rt overnight. To the mixture was added a mixture of bromo2-(bromomethyl)pyridine $(18 \mathrm{~g}, 70 \mathrm{mmol})$ in $\mathrm{THF}(80 \mathrm{~mL})$ and the mixture was stirred at $\mathrm{rt}$ 
overnight. The mixture was quenched with saturated aqueous $\mathrm{NH}_{4} \mathrm{Cl}$ and extracted with EtOAc. The organic layer was separated, washed with saturated aqueous $\mathrm{NaCl}$, dried over anhydrous $\mathrm{Na}_{2} \mathrm{SO}_{4}$, and concentrated in vacuo. The residue was purified by column chromatography (basic silica gel, hexane/EtOAc, 100:0 to 4:1) to give s6a (17 g, $55 \mathrm{mmol}, 79 \%)$ as a colorless oil. ${ }^{1} \mathrm{H}$ NMR $\left(300 \mathrm{MHz}, \mathrm{CDCl}_{3}\right) \delta 0.86(6 \mathrm{H}, \mathrm{d}, J=6.8 \mathrm{~Hz}), 0.98-1.14(1 \mathrm{H}, \mathrm{m}), 1.34-1.54(7 \mathrm{H}, \mathrm{m})$, 1.90-2.03 (2H, m), 3.65-3.78 (1H, m), $4.69(2 \mathrm{H}, \mathrm{s}), 7.11(1 \mathrm{H}, \mathrm{dd}, J=8.1,4.7 \mathrm{~Hz}), 7.86(1 \mathrm{H}, \mathrm{dd}$, $J=8.1,1.3 \mathrm{~Hz}), 8.53(1 \mathrm{H}, \mathrm{dd}, J=4.7,1.3 \mathrm{~Hz})$.

\section{3-Bromo-2-(((cis-4-methylcyclohexyl)oxy)methyl)pyridine (s6b)}

The title compound was prepared in $30 \%$ yield $(0.30 \mathrm{~g}, 35 \mathrm{mmol})$ as a colorless oil from $\mathbf{~ s 5 b}$

(1.2 $\mathrm{g}, 11 \mathrm{mmol})$ using the procedure analogous to that described for the synthesis of $\mathbf{s 6 a} .{ }^{1} \mathrm{H}$ NMR $\left(300 \mathrm{MHz}, \mathrm{CDCl}_{3}\right) \delta 0.90(3 \mathrm{H}, \mathrm{d}, J=6.0 \mathrm{~Hz}), 1.26-1.62(7 \mathrm{H}, \mathrm{m}), 1.84-2.07(2 \mathrm{H}, \mathrm{m}), 3.67$ $(1 \mathrm{H}, \mathrm{dd}, J=4.7,2.3 \mathrm{~Hz}), 4.70(2 \mathrm{H}, \mathrm{s}), 7.11(1 \mathrm{H}, \mathrm{dd}, J=8.1,4.7 \mathrm{~Hz}), 7.86(1 \mathrm{H}, \mathrm{dd}, J=8.0,1.4$ $\mathrm{Hz}), 8.54(1 \mathrm{H}, \mathrm{dd}, J=4.7,1.5 \mathrm{~Hz})$.

\section{3-Bromo-2-(((cis-4-phenylcyclohexyl)oxy)methyl)pyridine (s6c)}

The title compound was prepared in $85 \%$ yield $(84 \mathrm{~g}, 0.24 \mathrm{mmol})$ as a pale yellow oil from $\mathbf{s 5 c}$ (51 g, $0.29 \mathrm{~mol}$ ) using the procedure analogous to that described for the synthesis of s6a. ${ }^{1} \mathrm{H}$ NMR (300 MHz, $\left.\mathrm{CDCl}_{3}\right) \delta 1.56(2 \mathrm{H}, \mathrm{d}, J=3.0 \mathrm{~Hz}), 1.62-1.71(2 \mathrm{H}, \mathrm{m}), 1.87-2.01(2 \mathrm{H}, \mathrm{m})$, 2.11-2.21 (2H, m), 2.45-2.70 (1H, m), 3.79-3.89 (1H, m), $4.74(2 \mathrm{H}, \mathrm{s}), 7.09-7.20(2 \mathrm{H}, \mathrm{m})$, 7.20-7.26 (3H, m), 7.27-7.32 (1H, m), $7.88(1 \mathrm{H}, \mathrm{dd}, J=8.0,1.5 \mathrm{~Hz}), 8.47-8.59(1 \mathrm{H}, \mathrm{m})$. 
The mixture of s6a $(3.0 \mathrm{~g}, 9.6 \mathrm{mmol})$, methanesulfonamide $(1.1 \mathrm{~g}, 12 \mathrm{mmol})$, XPhos $(0.41 \mathrm{~g}$, $0.96 \mathrm{mmol}), \mathrm{Pd}_{2}(\mathrm{dba})_{3}(0.44 \mathrm{~g}, 0.48 \mathrm{mmol}), \mathrm{Cs}_{2} \mathrm{CO}_{3}(4.7 \mathrm{~g}, 14 \mathrm{mmol})$, and THF $(40 \mathrm{~mL})$ was heated at $120{ }^{\circ} \mathrm{C}$ for 20 min under microwave irradiation. The mixture was passed through a pad of Celite and the filtrate was extracted with EtOAc. The organic layer was separated, washed with water and saturated aqueous $\mathrm{NaCl}$, dried over anhydrous $\mathrm{MgSO}_{4}$, and concentrated in vacuo. The residue was purified by column chromatography (silica gel, hexane/EtOAc, 19:1 to 1:1) to give s7a $(2.3 \mathrm{~g}, 7.1 \mathrm{mmol}, 73 \%)$ as an orange oil. ${ }^{1} \mathrm{H} \mathrm{NMR}\left(300 \mathrm{MHz}, \mathrm{CDCl}_{3}\right) \delta 0.86(3 \mathrm{H}, \mathrm{s})$, $0.88(3 \mathrm{H}, \mathrm{s}), 1.00-1.16(1 \mathrm{H}, \mathrm{m}), 1.22-1.56(7 \mathrm{H}, \mathrm{m}), 1.89-2.08(2 \mathrm{H}, \mathrm{m}), 3.03(3 \mathrm{H}, \mathrm{s}), 3.63-3.77$ $(1 \mathrm{H}, \mathrm{m}), 4.81(2 \mathrm{H}, \mathrm{s}), 7.25(1 \mathrm{H}, \mathrm{dd}, J=8.5,4.7 \mathrm{~Hz}), 7.93(1 \mathrm{H}, \mathrm{dd}, J=8.3,1.5 \mathrm{~Hz}), 8.29(1 \mathrm{H}, \mathrm{dd}$, $J=4.5,1.5 \mathrm{~Hz}), 8.80(1 \mathrm{H}, \mathrm{s})$.

\section{$N$-(2-(((cis-4-Methylcyclohexyl)oxy)methyl)pyridin-3-yl)methanesulfonamide (s7b)}

The title compound was prepared in $57 \%$ yield $(0.63 \mathrm{~g}, 2.1 \mathrm{mmol})$ as a yellow oil from $\mathbf{s 6 b}(1.1$ g, $3.7 \mathrm{mmol}$ ) using the procedure analogous to that described for the synthesis of s7a. ${ }^{1} \mathrm{H}$ NMR $\left(300 \mathrm{MHz}, \mathrm{CDCl}_{3}\right) \delta$ 0.87-0.97 (3H, m), 1.18-1.62 (10H, m), 1.85-2.00 (2H, m), 3.66-3.75 (1H, m), 4.78-4.84 (2H, m), 7.21-7.25 (1H, m), 7.88-7.98 (1H, m), 8.25-8.32 (1H, m), 8.78 (1H, s).

\section{N-(2-(((cis-4-Phenylcyclohexyl)oxy)methyl)pyridin-3-yl)methanesulfonamide (s7c)}

The title compound was prepared in $75 \%$ yield $(2.3 \mathrm{~g}, 6.5 \mathrm{mmol})$ as a yellow solid from s6c $(3.0$ $\mathrm{g}, 8.7 \mathrm{mmol}$ ) using the procedure analogous to that described for the synthesis of $\mathbf{s} 7 \mathbf{a} .{ }^{1} \mathrm{H} \mathrm{NMR}$ $\left(300 \mathrm{MHz}, \mathrm{CDCl}_{3}\right) \delta 1.60-1.88(6 \mathrm{H}, \mathrm{m}), 2.11(2 \mathrm{H}, \mathrm{brs}), 2.46-2.67(1 \mathrm{H}, \mathrm{m}), 3.05(3 \mathrm{H}, \mathrm{s}), 3.82$ $(1 \mathrm{H}, \mathrm{t}, J=2.8 \mathrm{~Hz}), 4.86(2 \mathrm{H}, \mathrm{s}), 7.25(3 \mathrm{H}, \mathrm{s}), 7.27-7.35(3 \mathrm{H}, \mathrm{m}), 7.94(1 \mathrm{H}, \mathrm{dd}, J=8.3,1.5 \mathrm{~Hz})$, $8.30(1 \mathrm{H}, \mathrm{dd}, J=4.9,1.5 \mathrm{~Hz}), 8.79(1 \mathrm{H}, \mathrm{s})$. 
N-(cis-2-(((cis-4-Isopropylcyclohexyl)oxy)methyl)piperidin-3-yl)methanesulfonamide (s8a)

A mixture of s7a $(2.3 \mathrm{~g}, 7.1 \mathrm{mmol})$ and $\mathrm{PtO}_{2}(80 \mathrm{mg}, 0.35 \mathrm{mmol})$ in $\mathrm{MeOH}(15 \mathrm{~mL})$ and $\mathrm{AcOH}$ $(15 \mathrm{~mL})$ was hydrogenated under $87 \mathrm{psi}$ at $50{ }^{\circ} \mathrm{C}$ for $16 \mathrm{~h}$. The catalyst was removed by filtration and the filtrate was concentrated in vacuo. The residue was diluted with EtOAc, washed with saturated aqueous $\mathrm{NaHCO}_{3}$ and saturated aqueous $\mathrm{NaCl}$, and concentrated in vacuo. The residue was purified by column chromatography (basic silica gel, hexane/EtOAc, 100:0 to 2:3) to give s8a $(1.6 \mathrm{~g}, 4.9 \mathrm{mmol}, 69 \%)$ as a pale yellow oil. ${ }^{1} \mathrm{H}$ NMR $\left(300 \mathrm{MHz}, \mathrm{CDCl}_{3}\right) \delta 0.84(3 \mathrm{H}, \mathrm{s}), 0.87$ $(3 \mathrm{H}, \mathrm{s}), 0.96-1.11(1 \mathrm{H}, \mathrm{m}), 1.19-2.03(14 \mathrm{H}, \mathrm{m}), 2.66(1 \mathrm{H}, \mathrm{td}, J=11.8,2.8 \mathrm{~Hz}), 2.86(1 \mathrm{H}, \mathrm{ddd}, J$ $=7.8,4.4,2.1 \mathrm{~Hz}), 2.97(3 \mathrm{H}, \mathrm{s}), 3.04(1 \mathrm{H}, \mathrm{dt}, J=11.5,2.4 \mathrm{~Hz}), 3.33(1 \mathrm{H}, \mathrm{dd}, J=9.4,7.9 \mathrm{~Hz})$, $3.46(2 \mathrm{H}, \mathrm{dd}, J=9.4,4.5 \mathrm{~Hz}), 3.59(1 \mathrm{H}, \mathrm{brs}), 5.36(1 \mathrm{H}, \mathrm{d}, J=7.2 \mathrm{~Hz})$.

\section{N-(cis-2-(((cis-4-Methylcyclohexyl)oxy)methyl)piperidin-3yl)methanesulfonamide (s8b)}

The title compound was prepared in $70 \%$ yield $(443 \mathrm{mg}, 1.5 \mathrm{mmol})$ as a yellow solid from $\mathbf{~ s 7 b}$ (620 mg, $2.1 \mathrm{mmol}$ ) using the procedure analogous to that described for the synthesis of s8a. ${ }^{1} \mathrm{H}$ NMR (300 MHz, $\left.\mathrm{CDCl}_{3}\right) \delta$ 0.84-0.95 (3H, m), 1.14-1.33 (2H, m), 1.35-1.87 (11H, m),

1.90-2.02 (1H, m), 2.57-2.74 (1H, m), 2.80-2.89 (1H, m), $2.97(3 \mathrm{H}, \mathrm{s}), 3.01-3.11(1 \mathrm{H}, \mathrm{m})$, 3.25-3.39 (1H, m), 3.42-3.52 (2H, m), 3.55-3.66 (1H, m), 5.20-5.49 (1H, m).

\section{$N$-(cis-2-(cis-4-Phenylcyclohexyloxymethyl)-piperidin-3-yl)-methanesulfonamide (s8c)}

A mixture of s7c $(1.0 \mathrm{~g}, 2.8 \mathrm{mmol})$ and $\mathrm{PtO}_{2}(63 \mathrm{mg}, 0.28 \mathrm{mmol})$ in $\mathrm{MeOH}(24 \mathrm{~mL})$ and $\mathrm{AcOH}$ $(8 \mathrm{~mL})$ was hydrogenated under balloon pressure at $50{ }^{\circ} \mathrm{C}$ for $4 \mathrm{~h}$. The catalyst was removed by 
filtration and the filtrate was concentrated in vacuo. The residue was purified by column chromatography (basic silica gel, hexane/EtOAc, 7:3 to 0:100) to afford s8c (0.69 g, $1.9 \mathrm{mmol}$, $47 \%)$ as a waxy solid. ${ }^{1} \mathrm{H}$ NMR $\left(400 \mathrm{MHz} \mathrm{CDCl}_{3}\right) \delta 1.49-1.78(9 \mathrm{H}, \mathrm{m}), 1.95-2.02(3 \mathrm{H}, \mathrm{m})$, 2.48-2.56 (1H, m), 2.65-2.71 (1H, m), 2.87-2.90 (1H, m), $2.96(3 \mathrm{H}, \mathrm{s}), 3.02-3.05(1 \mathrm{H}, \mathrm{m}), 3.36$ $(1 \mathrm{H}, \mathrm{t}, J=9.2 \mathrm{~Hz}), 3.48-3.51(1 \mathrm{H}, \mathrm{m}), 3.58-3.62(2 \mathrm{H}, \mathrm{m}), 5.37(1 \mathrm{H}, \mathrm{d}, J=7.6 \mathrm{~Hz}), 7.15-7.28$ $(5 \mathrm{H}, \mathrm{m})$.

\section{N-(cis-1-Acetyl-2-(((cis-4-isopropylcyclohexyl)oxy)methyl)piperidin-3- yl)methanesulfonamide (7)}

To a mixture of s8a $(0.10 \mathrm{~g}, 0.30 \mathrm{mmol})$ and DIEA $(0.079 \mathrm{~mL}, 0.45 \mathrm{mmol})$ in DMA $(5 \mathrm{~mL})$ was added $\mathrm{AcCl}$ (35 mg, $0.45 \mathrm{mmol}$ ) at $\mathrm{rt}$. The mixture was stirred at $\mathrm{rt}$ overnight. The mixture was poured into water and extracted with EtOAc. The organic layer was separated, washed with $1 \mathrm{~N}$ $\mathrm{HCl}$ aqueous solution and saturated aqueous $\mathrm{NaCl}$, dried over anhydrous $\mathrm{MgSO}_{4}$, and concentrated in vacuo. The residue was purified by column chromatography (silica gel, hexane/EtOAc, $1: 9$ to $0: 100)$ to give $7(0.11 \mathrm{~g}, 0.29 \mathrm{mmol}, 98 \%)$ as an amorphous solid. ${ }^{1} \mathrm{H}$ NMR $\left(300 \mathrm{MHz}, \mathrm{CDCl}_{3}\right) \delta$ 0.76-0.95 (6H, m), 0.99-2.26 (17H, m), 2.44-3.17 (4H, m), 3.38-6.33 (7H, m). MS (ESI/APCI) mass calculated for $[\mathrm{M}+\mathrm{H}]^{+}\left(\mathrm{C}_{18} \mathrm{H}_{35} \mathrm{~N}_{2} \mathrm{O}_{4} \mathrm{~S}\right)$ requires $\mathrm{m} / \mathrm{z} 374.5$, found $\mathrm{m} / \mathrm{z}$ 375.2

\section{$N$-(cis-1-Acetyl-2-(((cis-4-isopropylcyclohexyl)oxy)methyl)piperidin-3-yl)- $N$ - methylmethanesulfonamide (10)}

To a mixture of $7(0.11 \mathrm{~g}, 0.30 \mathrm{mmol})$ in DMA $(10 \mathrm{~mL})$ was added $60 \% \mathrm{NaH}$ in oil $(18 \mathrm{mg}$, $0.45 \mathrm{mmol})$ at $0{ }^{\circ} \mathrm{C}$. After being stirred at $0{ }^{\circ} \mathrm{C}$ for $10 \mathrm{~min}$, MeI $(0.028 \mathrm{~mL}, 0.45 \mathrm{mmol})$ was 
added to the reaction mixture at $0{ }^{\circ} \mathrm{C}$. The mixture was stirred at $0{ }^{\circ} \mathrm{C}$ for $1 \mathrm{~h}$. The mixture was neutralized with $1 \mathrm{~N} \mathrm{HCl}$ aqueous solution at $0{ }^{\circ} \mathrm{C}$ and extracted with EtOAc. The organic layer was separated, washed with water and saturated aqueous $\mathrm{NaCl}$, dried over anhydrous $\mathrm{MgSO}_{4}$, and concentrated in vacuo. The residue was purified by column chromatography (silica gel, hexane/EtOAc, 17:3 to 0:100) to give $10(0.11 \mathrm{~g}, 0.28 \mathrm{mmol}, 94 \%)$ as a white solid. ${ }^{1} \mathrm{H}$ NMR $\left(300 \mathrm{MHz}, \mathrm{CDCl}_{3}\right) \delta$ 0.75-0.94 (6H, m), 0.98-2.23 (16H, m), 2.25-3.07 (7H, m), 3.36-4.31 (6H, m), 4.50-4.83 (1H, m). MS (ESI/APCI) mass calculated for $[\mathrm{M}+\mathrm{H}]^{+}\left(\mathrm{C}_{19} \mathrm{H}_{37} \mathrm{~N}_{2} \mathrm{O}_{4} \mathrm{~S}\right)$ requires $\mathrm{m} / \mathrm{z} 388.6$, found $\mathrm{m} / \mathrm{z} 389.4$.

\section{N-(cis-1-Acetyl-2-(((cis-4-methylcyclohexyl)oxy)methyl)piperidin-3-yl)methanesulfonamide} (12)

To a mixture of $\mathbf{s 8 b}(50 \mathrm{mg}, 0.16 \mathrm{mmol})$ and $\mathrm{Et}_{3} \mathrm{~N}(28 \mathrm{mg}, 0.28 \mathrm{mmol})$ in $\mathrm{THF}(5 \mathrm{~mL})$ was added $\mathrm{Ac}_{2} \mathrm{O}(25 \mathrm{mg}, 0.25 \mathrm{mmol})$ at $0{ }^{\circ} \mathrm{C}$. The mixture was stirred at $\mathrm{rt}$ for $15 \mathrm{~h}$. The mixture was poured into water at rt and was extracted with EtOAc. The organic layer was separated, washed with saturated aqueous $\mathrm{NaCl}$, dried over anhydrous $\mathrm{MgSO}_{4}$, and concentrated in vacuo. The residue was purified by column chromatography (silica gel, EtOAc/MeOH, 100:0 to 0:100) to give $12(52 \mathrm{mg}, 0.15 \mathrm{mmol}, 92 \%)$ as a pale yellow oil. ${ }^{1} \mathrm{H}$ NMR $\left(300 \mathrm{MHz}, \mathrm{CDCl}_{3}\right) \delta 0.80-0.98$ $(3 \mathrm{H}, \mathrm{m}), 1.09-1.33(3 \mathrm{H}, \mathrm{m}), 1.35-1.66(8 \mathrm{H}, \mathrm{m}), 1.71-1.91(4 \mathrm{H}, \mathrm{m}), 1.95-3.18(6 \mathrm{H}, \mathrm{m})$, 3.39-6.29 (6H, m). MS (ESI/APCI) mass calculated for $[\mathrm{M}+\mathrm{H}]^{+}\left(\mathrm{C}_{16} \mathrm{H}_{31} \mathrm{~N}_{2} \mathrm{O}_{4} \mathrm{~S}\right)$ requires $\mathrm{m} / \mathrm{z}$ 346.5, found $\mathrm{m} / \mathrm{z} 347.1$.

\section{$N$-(cis-1-Acetyl-2-(((cis-4-phenylcyclohexyl)oxy)methyl)piperidin-3-yl)methanesulfonamide} (13) 
To a mixture of s8c $(0.25 \mathrm{~g}, 0.68 \mathrm{mmol})$ and $\mathrm{Et}_{3} \mathrm{~N}(0.24 \mathrm{~mL}, 1.7 \mathrm{mmol})$ in THF $(5 \mathrm{~mL})$ was added $\mathrm{Ac}_{2} \mathrm{O}(0.096 \mathrm{~mL}, 1.0 \mathrm{mmol})$ at $\mathrm{rt}$. The reaction mixture was stirred at $\mathrm{rt}$ overnight. The mixture was quenched with saturated aqueous $\mathrm{NaHCO}_{3}$ and extracted with EtOAc three times. The organic layer was separated, washed with brine, dried over anhydrous $\mathrm{MgSO}_{4}$, and concentrated in vacuo. The residue was purified by column chromatography (basic silica gel, hexane/EtOAc, 7:3 to 1:4) to give $13(0.25 \mathrm{~g}, 0.61 \mathrm{mmol}, 89 \%)$ as a colorless oil. ${ }^{1} \mathrm{H}$ NMR (300 $\left.\mathrm{MHz}, \mathrm{CDCl}_{3}\right) \delta$ 1.55-2.64 (17H, m), 2.95-3.15 (4H, m), 3.54-3.71 (3H, m), 3.86-4.02 (1H, m), 4.29-6.26 (2H, m), 7.08-7.38 (5H, m). MS (ESI/APCI) mass calculated for $[\mathrm{M}+\mathrm{H}]^{+}$ $\left(\mathrm{C}_{21} \mathrm{H}_{33} \mathrm{~N}_{2} \mathrm{O}_{4} \mathrm{~S}\right)$ requires $\mathrm{m} / \mathrm{z} 408.6$, found $\mathrm{m} / \mathrm{z} 409.1$.

\section{$N$-(rel-(2R,3S)-1-Acetyl-2-(((cis-4-phenylcyclohexyl)oxy)methyl)piperidin-3-} yl)methanesulfonamide (13a)

Resolution of the enantiomers of $\mathbf{1 3}$ was carried out chromatographically using a Chiralcel OJ $50 \mathrm{~mm} \mathrm{ID} \times 500 \mathrm{mmL}$ column (hexane/EtOH, 600:400) at $60 \mathrm{~mL} / \mathrm{min}$. Resolution of $13(0.25 \mathrm{~g}$, $0.60 \mathrm{mmol})$ provided 13a $(0.11 \mathrm{~g}, 0.26 \mathrm{mmol}, 43 \%)$ as an amorphous solid. Analytical HPLC analysis carried out on a $4.6 \mathrm{~mm}$ ID $\times 250 \mathrm{mmL}$ Chiralcel OJ column (hexane/EtOH, 600:400) at a flow rate of $0.5 \mathrm{~mL} / \mathrm{min}$ indicated that $\mathbf{1 3 a}$ was of $>99.9 \%$ enantiomeric excess (ee). ${ }^{1} \mathrm{H}$ NMR $\left(300 \mathrm{MHz}, \mathrm{CDCl}_{3}\right) \delta$ 1.55-2.64 (17H, m), 2.95-3.15 (4H, m), 3.54-3.71 (3H, m), 3.86-4.02 (1H, $\mathrm{m}), 4.29-6.26(2 \mathrm{H}, \mathrm{m}), 7.08-7.38(5 \mathrm{H}, \mathrm{m})$. MS (ESI/APCI) mass calculated for $[\mathrm{M}+\mathrm{H}]^{+}$ $\left(\mathrm{C}_{21} \mathrm{H}_{33} \mathrm{~N}_{2} \mathrm{O}_{4} \mathrm{~S}\right)$ requires $\mathrm{m} / \mathrm{z} 408.6$, found $\mathrm{m} / \mathrm{z} 409.2$.

\section{$N$-(rel-(2S,3R)-1-Acetyl-2-(((cis-4-phenylcyclohexyl)oxy)methyl)piperidin-3-}




\section{yl)methanesulfonamide (13b)}

Resolution of the enantiomers of $\mathbf{1 3}$ was carried out chromatographically using a Chiralcel OJ $50 \mathrm{~mm} \mathrm{ID} \times 500 \mathrm{mmL}$ column (hexane/EtOH, 600:400) at $60 \mathrm{~mL} / \mathrm{min}$. Resolution of $13(0.25 \mathrm{~g}$, $0.60 \mathrm{mmol})$ provided $\mathbf{1 3 b}(0.11 \mathrm{~g}, 0.26 \mathrm{mmol}, 43 \%)$ as an amorphous solid. Analytical HPLC analysis carried out on a $4.6 \mathrm{~mm}$ ID $\times 250 \mathrm{~mm}$ L Chiralcel OJ column (hexane/EtOH, 600:400) at a flow rate of $0.5 \mathrm{~mL} / \mathrm{min}$ indicated that $\mathbf{1 3 b}$ was of $99.8 \%$ ee. ${ }^{1} \mathrm{H} \mathrm{NMR}\left(300 \mathrm{MHz}, \mathrm{CDCl}_{3}\right) \delta$ 1.55-2.64 (17H, m), 2.95-3.15 (4H, m), 3.54-3.71 (3H, m), 3.86-4.02 (1H, m), 4.29-6.26 (2H, m), 7.08-7.38 (5H, m). MS (ESI/APCI) mass calculated for $[\mathrm{M}+\mathrm{H}]^{+}\left(\mathrm{C}_{21} \mathrm{H}_{33} \mathrm{~N}_{2} \mathrm{O}_{4} \mathrm{~S}\right)$ requires $\mathrm{m} / \mathrm{z} 408.6$, found $\mathrm{m} / \mathrm{z} 409.1$. 


\section{Synthesis of 8,9 and $11^{a}$}
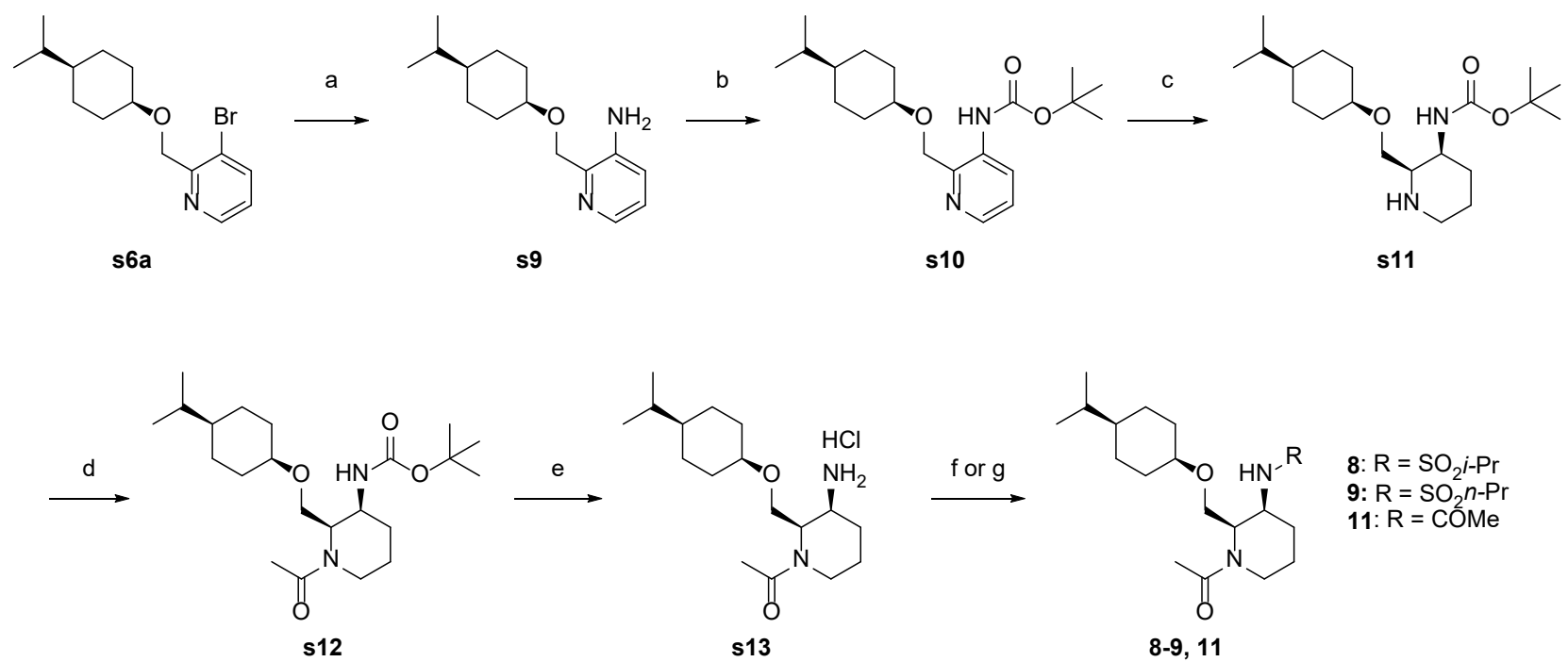

${ }^{a}$ All compounds are racemic mixtures. Reagents and conditions: (a) (1) diphenylmethanimine, $\mathrm{Pd}_{2}(\mathrm{dba})_{3}, \mathrm{XPhos}, \mathrm{NaO} t$-Bu, toluene, $80{ }^{\circ} \mathrm{C}$; (2) $2 \mathrm{~N} \mathrm{HCl}$, THF, rt; (b) $\mathrm{Boc}_{2} \mathrm{O}, 1.9 \mathrm{M}$ NaHMDS in THF, THF, rt; (c) $\mathrm{H}_{2}$ (87 psi), $\mathrm{PtO}_{2}, \mathrm{AcOH}, \mathrm{MeOH}$, rt; (d) AcCl, DIEA, DMA, rt; (e) 4 N HCl in EtOAc, EtOAc, rt; (f) $\mathrm{RSO}_{2} \mathrm{Cl}$ (for 8 and 9), DBU, THF, rt; (g) AcCl, DIEA, DMA, rt (for 11).

\section{2-(((cis-4-Isopropylcyclohexyl)oxy)methyl)pyridin-3-amine (s9)}

The title compound was prepared in $77 \%$ yield $(1.3 \mathrm{~g}, 5.0 \mathrm{mmol})$ as a white solid from s6a $(3.1$ g, $10 \mathrm{mmol}$ ) using the procedure analogous to that described for the synthesis of s3. ${ }^{1} \mathrm{H}$ NMR $\left(300 \mathrm{MHz}, \mathrm{CDCl}_{3}\right) \delta 0.80-0.90(6 \mathrm{H}, \mathrm{m}), 0.98-1.16(1 \mathrm{H}, \mathrm{m}), 1.25-1.52(7 \mathrm{H}, \mathrm{m}), 1.88-2.02(2 \mathrm{H}$, m), $3.64(1 \mathrm{H}$, brs $), 4.40(2 \mathrm{H}$, brs $), 4.65-4.74(2 \mathrm{H}, \mathrm{m}), 6.91-6.99(1 \mathrm{H}, \mathrm{m}), 7.03(1 \mathrm{H}, \mathrm{dd}, J=7.9$, $4.5 \mathrm{~Hz}), 7.93(1 \mathrm{H}, \mathrm{dd}, J=4.5,1.5 \mathrm{~Hz})$. 
To a mixture of s9 $(0.66 \mathrm{~g}, 3,0 \mathrm{mmol})$ in THF $(20 \mathrm{~mL})$ was added $1.9 \mathrm{M}$ NaHMDS in THF (3.3 $\mathrm{mL}, 6.3 \mathrm{mmol})$ at $\mathrm{rt}$ and the resulting mixture was stirred at $\mathrm{rt}$ for $10 \mathrm{~min}$. $\mathrm{Boc}_{2} \mathrm{O}(0.70 \mathrm{~mL}, 3.0$ mmol) was added to the mixture at $\mathrm{rt}$, and the resulting mixture was stirred at $\mathrm{rt}$ overnight. The mixture was poured into water and extracted with EtOAc. The organic layer was separated, washed with saturated aqueous $\mathrm{NaCl}$, dried over anhydrous $\mathrm{MgSO}_{4}$, and concentrated in vacuo. The residue was purified by column chromatography (silica gel, hexane/EtOAc, 100:0 to 1:1) to give s10 (0.55 g, $1.6 \mathrm{mmol}, 53 \%)$ as a pale yellow oil. ${ }^{1} \mathrm{H}$ NMR (300 MHz, DMSO- $\left.d_{6}\right) \delta 0.83$ $(6 \mathrm{H}, \mathrm{d}, J=6.8 \mathrm{~Hz}), 0.95-1.54(17 \mathrm{H}, \mathrm{m}), 1.78-1.92(2 \mathrm{H}, \mathrm{m}), 3.58-3.68(1 \mathrm{H}, \mathrm{m}), 4.69(2 \mathrm{H}, \mathrm{s})$, 7.24-7.38 (1H, m), 8.09-8.22 (2H, m), 8.51-8.65 (1H, m).

\section{tert-Butyl (cis-2-(((cis-4-isopropylcyclohexyl)oxy)methyl)piperidin-3-yl)carbamate (s11)}

A mixture of s10 $(0.54 \mathrm{~g}, 1.6 \mathrm{mmol})$ and $\mathrm{PtO}_{2}(18 \mathrm{mg}, 0.080 \mathrm{mmol})$ in $\mathrm{MeOH}(10 \mathrm{~mL})$ and $\mathrm{AcOH}(10 \mathrm{~mL})$ was hydrogenated under $87 \mathrm{psi}$ at $\mathrm{rt}$ overnight. The catalyst was removed by filtration and the filtrate was neutralized with $1 \mathrm{~N} \mathrm{NaOH}$ aqueous solution at $0{ }^{\circ} \mathrm{C}$ and extracted with EtOAc. The organic layer was separated, washed with saturated aqueous $\mathrm{NaCl}$, dried over anhydrous $\mathrm{Na}_{2} \mathrm{SO}_{4}$, and concentrated in vacuo. The residue was purified by column chromatography (basic silica gel, hexane/EtOAc, 100:0 to $3: 2)$ to give s11 (0.29 g, $0.82 \mathrm{mmol}$, $53 \%)$ as a white solid. ${ }^{1} \mathrm{H}$ NMR $\left(300 \mathrm{MHz} \mathrm{CDCl}_{3}\right) \delta 0.81-0.90(6 \mathrm{H}, \mathrm{m}), 0.93-1.13(1 \mathrm{H}, \mathrm{m})$, 1.17-1.55 (16H, m), $1.56(1 \mathrm{H}$, brs $), 1.65(5 \mathrm{H}, \mathrm{brs}), 1.84(3 \mathrm{H}, \mathrm{brs}), 2.57-2.75(1 \mathrm{H}, \mathrm{m}), 2.85(1 \mathrm{H}$, $\mathrm{d}, J=9.1 \mathrm{~Hz}), 2.98-3.12(1 \mathrm{H}, \mathrm{m}), 3.20(1 \mathrm{H}, \mathrm{t}, J=9.3 \mathrm{~Hz}), 3.38-3.52(2 \mathrm{H}, \mathrm{m}), 3.71(1 \mathrm{H}, \mathrm{d}, J=$ $7.2 \mathrm{~Hz}), 5.37(1 \mathrm{H}, \mathrm{d}, J=9.1 \mathrm{~Hz})$. 
tert-Butyl (cis-1-acetyl-2-(((cis-4-isopropylcyclohexyl)oxy)methyl)piperidin-3-yl)carbamate (s12)

To a mixture of $\mathbf{s 1 1}(0.36 \mathrm{~g}, 1.0 \mathrm{mmol})$ and DIEA $(0.21 \mathrm{~mL}, 1.2 \mathrm{mmol})$ in DMA $(10 \mathrm{~mL})$ was added $\mathrm{AcCl}(0.085 \mathrm{~mL}, 1.2 \mathrm{mmol})$ at $\mathrm{rt}$. The mixture was stirred at $\mathrm{rt}$ overnight. The mixture was poured into water and extracted with EtOAc. The organic layer was separated, washed with $1 \mathrm{~N}$ $\mathrm{HCl}$ aqueous solution and saturated aqueous $\mathrm{NaCl}$, dried over anhydrous $\mathrm{MgSO}_{4}$, and concentrated in vacuo. The residue was purified by column chromatography (silica gel, hexane/EtOAc, 9:1 to 0:100) to give s12 (0.29 g, $0.73 \mathrm{mmol}, 73 \%)$ as a white amorphous solid. ${ }^{1} \mathrm{H}$ NMR (300 MHz, DMSO-d $\left.d_{6}\right) \delta$ 0.67-0.89 (6H, m), 0.96-2.09 (25H, m), 2.93-3.68 (6H, m), 4.14-4.95 (2H, m), 6.67-7.12 (1H, m).

\section{1-(cis-3-Amino-2-(((cis-4-isopropylcyclohexyl)oxy)methyl)piperidin-1-yl)ethanone hydrochloride (s13)}

To a mixture of $\mathbf{s 1 2}(0.31 \mathrm{mg}, 0.77 \mathrm{mmol})$ in EtOAc $(2 \mathrm{~mL})$ was added $4 \mathrm{~N} \mathrm{HCl}$ in EtOAc $(0.96$ $\mathrm{mL}, 3.9 \mathrm{mmol}$ ) at $\mathrm{rt}$. The mixture was stirred at $\mathrm{rt}$ under $\mathrm{N}_{2}$ for $1 \mathrm{~h}$. The solvent was evaporated in vacuo to give s13 (0.25 g, $0.75 \mathrm{mmol}, 98 \%)$ as an amorphous solid. ${ }^{1} \mathrm{H}$ NMR (300 MHz, DMSOd6) $\delta$ 0.70-0.91 (6H, m), 0.96-1.50 (8H, m), 1.66-2.11 (8H, m), 2.22-2.47 (3H, m), 2.93-3.19 (1H, m), 3.43-3.77 (3H, m), 4.22-5.11 (2H, m), 7.84-8.11 (2H, m).

\section{$N$-(cis-1-Acetyl-2-(((cis-4-isopropylcyclohexyl)oxy)methyl)piperidin-3-yl)propane-2-} sulfonamide (8)

To a mixture of s13 (44 mg, $0.13 \mathrm{mmol})$ in THF ( $5 \mathrm{~mL})$ was added DBU (80 mg, $0.53 \mathrm{mmol})$ at 
$0{ }^{\circ} \mathrm{C}$. After being stirred at $0{ }^{\circ} \mathrm{C}$ for $10 \mathrm{~min}$, propane-2-sulfonyl chloride (38 $\mathrm{mg}, 0.26 \mathrm{mmol}$ ) was added to the reaction mixture at $\mathrm{rt}$. The mixture was stirred at rt overnight. After concentration in vacuo, the residue was purified by column chromatography (silica gel, hexane/EtOAc, 80:20 to 0:100) to give $8(15 \mathrm{mg}, 0.037 \mathrm{mmol}, 28 \%)$ as oil. ${ }^{1} \mathrm{H}$ NMR $\left(300 \mathrm{MHz}, \mathrm{CDCl}_{3}\right) \delta 0.86(6 \mathrm{H}, \mathrm{d}, J=$ $6.8 \mathrm{~Hz}), 0.99-2.35(23 \mathrm{H}, \mathrm{m}), 2.45-3.26(2 \mathrm{H}, \mathrm{m}), 3.35-6.04(7 \mathrm{H}, \mathrm{m}) . \mathrm{MS}$ (ESI/APCI) mass calculated for $[\mathrm{M}+\mathrm{H}]^{+}\left(\mathrm{C}_{20} \mathrm{H}_{39} \mathrm{~N}_{2} \mathrm{O}_{4} \mathrm{~S}\right)$ requires $\mathrm{m} / \mathrm{z} 402.6$, found $\mathrm{m} / \mathrm{z} 403.1$.

\section{$N$-(cis-1-Acetyl-2-(((cis-4-isopropylcyclohexyl)oxy)methyl)piperidin-3-yl)propane-1-}

\section{sulfonamide (9)}

To a mixture of s13 (48 mg, $0.14 \mathrm{mmol})$ in THF ( $5 \mathrm{~mL})$ was added DBU (87 mg, $0.57 \mathrm{mmol})$ at $0{ }^{\circ} \mathrm{C}$. After being stirred at $0{ }^{\circ} \mathrm{C}$ for $10 \mathrm{~min}$, propane-1-sulfonyl chloride (41 $\mathrm{mg}, 0.29 \mathrm{mmol}$ ) was added to the reaction mixture at $\mathrm{rt}$. The mixture was stirred at $\mathrm{rt}$ overnight. After concentration in vacuo, the residue was purified by column chromatography (silica gel, hexane/EtOAc, 80:20 to 0:100) to give $9(34 \mathrm{mg}, 0.084 \mathrm{mmol}, 59 \%)$ as oil. ${ }^{1} \mathrm{H}$ NMR $\left(300 \mathrm{MHz}, \mathrm{CDCl}_{3}\right) \delta 0.86(6 \mathrm{H}, \mathrm{d}, J=$ $6.8 \mathrm{~Hz}), 0.97-2.29(22 \mathrm{H}, \mathrm{m}), 2.50-3.20(3 \mathrm{H}, \mathrm{m}), 3.28-6.19(7 \mathrm{H}, \mathrm{m}) . \mathrm{MS}$ (ESI/APCI) mass calculated for $[\mathrm{M}+\mathrm{H}]^{+}\left(\mathrm{C}_{20} \mathrm{H}_{39} \mathrm{~N}_{2} \mathrm{O}_{4} \mathrm{~S}\right)$ requires $\mathrm{m} / \mathrm{z}$ 402.6, found $\mathrm{m} / \mathrm{z} 403.2$.

\section{$N$-(cis-1-Acetyl-2-(((cis-4-isopropylcyclohexyl)oxy)methyl)piperidin-3-yl)acetamide (11)}

To a mixture of s13 $(83 \mathrm{mg}, 0.25 \mathrm{mmol})$ and DIEA (0.087 mL, $0.50 \mathrm{mmol})$ in DMA (4 mL) was added $\mathrm{AcCl}(0.027 \mathrm{~mL}, 0.38 \mathrm{mmol})$ at $\mathrm{rt}$. The mixture was stirred at $\mathrm{rt}$ overnight. The mixture was poured into water and extracted with EtOAc. The organic layer was separated, washed with saturated aqueous $\mathrm{NaCl}$, dried over $\mathrm{MgSO}_{4}$, and concentrated in vacuo. The residue was purified by column chromatography (silica gel, EtOAc/MeOH, 100:0 to 7:3) to give 11 (63 mg, 0.19 
mmol, $74 \%)$ as a colorless oil. ${ }^{1} \mathrm{H}$ NMR $\left(300 \mathrm{MHz}, \mathrm{CDCl}_{3}\right) \delta 0.87(6 \mathrm{H}, \mathrm{d}, J=6.8 \mathrm{~Hz}), 1.00-1.16$ $(1 \mathrm{H}, \mathrm{m}), 1.16-2.26(19 \mathrm{H}, \mathrm{m}), 2.41-3.70(4 \mathrm{H}, \mathrm{m}), 3.74-4.10(2 \mathrm{H}, \mathrm{m}), 4.18-4.64(1 \mathrm{H}, \mathrm{m})$, 4.88-6.62 (1H, m). MS (ESI/APCI) mass calculated for $[\mathrm{M}+\mathrm{H}]^{+}\left(\mathrm{C}_{19} \mathrm{H}_{35} \mathrm{~N}_{2} \mathrm{O}_{3}\right)$ requires $\mathrm{m} / \mathrm{z}$ 338.5 , found $\mathrm{m} / \mathrm{z} 339.3$.

\section{Synthesis of 14, 15, 16, 17 and $18^{a}$}

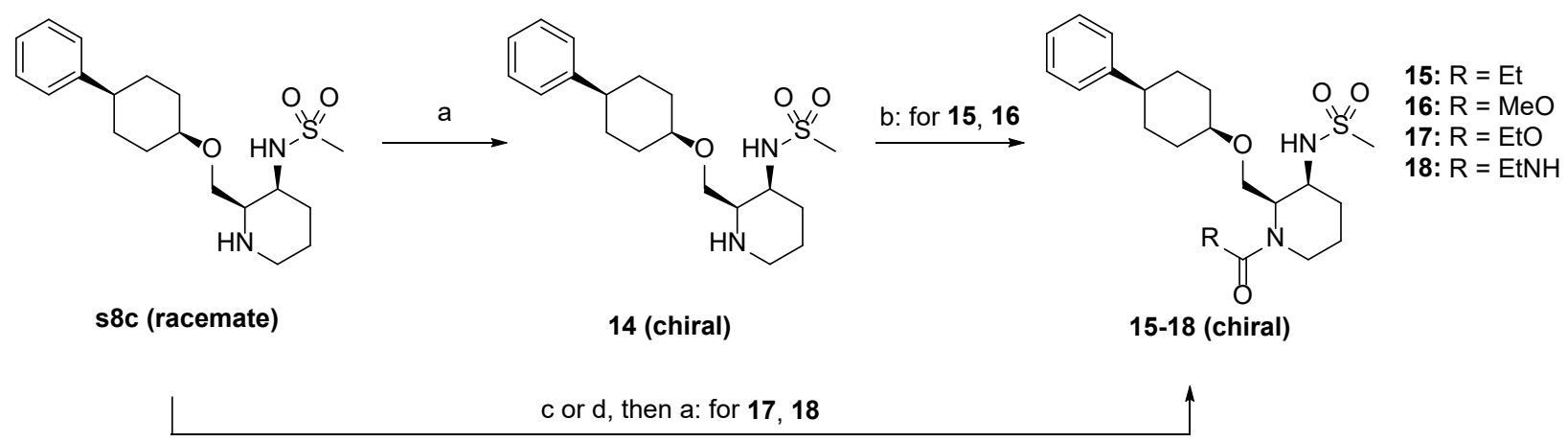

${ }^{a}$ Reagents and conditions: (a) chiral column separation; (b) RCOCl, Et 3 N, THF, rt (for $\mathbf{1 5}$ and 16); (c) ethyl chlorocarbonate, DIEA, THF, $\mathrm{rt}$ (for 17); (d) isocyanatoethane, $\mathrm{Et}_{3} \mathrm{~N}, \mathrm{THF}, 0{ }^{\circ} \mathrm{C}-\mathrm{rt}$ (for 18).

\section{$N$-(rel-(2R,3S)-2-(((cis-4-Phenylcyclohexyl)oxy)methyl)piperidin-3-yl)methanesulfonamide}

Resolution of the enantiomers of s8c was carried out chromatographically using a Chiralpak AD $50 \mathrm{~mm} \mathrm{ID} \times 500 \mathrm{mmL}$ column (hexane/EtOH$\left./ \mathrm{Et}_{2} \mathrm{NH}, 700: 300: 1\right)$ at $60 \mathrm{~mL} / \mathrm{min}$. Resolution of s8c $(4.3 \mathrm{~g}, 12 \mathrm{mmol})$ provided $14(1.6 \mathrm{~g}, 4.4 \mathrm{mmol}, 38 \%)$ as oil. Analytical HPLC analysis carried out on a $4.6 \mathrm{~mm}$ ID $\times 250 \mathrm{~mm}$ L Chiralpak AD column (hexane/EtOH/Et $2 \mathrm{NH}, 700: 300: 1$ ) at a flow rate of $0.5 \mathrm{~mL} / \mathrm{min}$ indicated that 14 was of $>99.9 \%$ ee. ${ }^{1} \mathrm{H}$ NMR $\left(600 \mathrm{MHz}\right.$, DMSO- $\left.d_{6}\right)$ $\delta 1.31-1.38(1 \mathrm{H}, \mathrm{m}), 1.45-1.55(5 \mathrm{H}, \mathrm{m}), 1.63-1.84(4 \mathrm{H}, \mathrm{m}), 1.87-1.98(3 \mathrm{H}, \mathrm{m}), 2.50-2.56(2 \mathrm{H}$, 
m), $2.79(1 \mathrm{H}, \mathrm{td}, J=6.6,2.6 \mathrm{~Hz}), 2.87-2.92(1 \mathrm{H}, \mathrm{m}), 2.93(3 \mathrm{H}, \mathrm{s}), 3.28-3.33(1 \mathrm{H}, \mathrm{m}), 3.34-3.39$ $(1 \mathrm{H}, \mathrm{m}), 3.50(1 \mathrm{H}, \mathrm{brs}), 3.57(1 \mathrm{H}$, brquin, $J=3.0 \mathrm{~Hz}), 6.70(1 \mathrm{H}, \mathrm{brs}), 7.16(1 \mathrm{H}, \mathrm{t}, J=6.9 \mathrm{~Hz})$, $7.21(2 \mathrm{H}, \mathrm{d}, J=7.4 \mathrm{~Hz}), 7.27(2 \mathrm{H}, \mathrm{t}, J=7.6 \mathrm{~Hz})$. MS (ESI/APCI) mass calculated for $[\mathrm{M}+\mathrm{H}]^{+}$ $\left(\mathrm{C}_{19} \mathrm{H}_{31} \mathrm{~N}_{2} \mathrm{O}_{3} \mathrm{~S}\right)$ requires $\mathrm{m} / \mathrm{z} 366.5$, found $\mathrm{m} / \mathrm{z} 367.1$.

\section{N-(rel-(2R,3S)-2-(((cis-4-Phenylcyclohexyl)oxy)methyl)-1-propionylpiperidin-3-}

\section{yl)methanesulfonamide (15)}

To a mixture of $14(58 \mathrm{mg}, 0.16 \mathrm{mmol})$ and $\mathrm{Et}_{3} \mathrm{~N}(0.044 \mathrm{~mL}, 0.32 \mathrm{mmol})$ in $\mathrm{THF}(3 \mathrm{~mL})$ was added propionyl chloride $(0.021 \mathrm{~mL}, 0.24 \mathrm{mmol})$ at $\mathrm{rt}$. The mixture was stirred at $\mathrm{rt}$. The mixture was quenched with water and extracted with EtOAc. The organic layer was separated, washed with saturated aqueous $\mathrm{NaCl}$, dried over anhydrous $\mathrm{Na}_{2} \mathrm{SO}_{4}$, and concentrated in vacuo. The residue was purified by column chromatography (silica gel, hexane/EtOAc, 2:3 to 0:100) to give $15(67 \mathrm{mg}, 0.16 \mathrm{mmol}, 100 \%)$ as a colorless oil. ${ }^{1} \mathrm{H} \mathrm{NMR}\left(300 \mathrm{MHz}, \mathrm{CDCl}_{3}\right) \delta 1.15(3 \mathrm{H}, \mathrm{t}, J=$ $7.4 \mathrm{~Hz}), 1.54-1.63(6 \mathrm{H}, \mathrm{m}), 1.70-1.85(4 \mathrm{H}, \mathrm{m}), 1.92-2.09(3 \mathrm{H}, \mathrm{m}), 2.24-2.67(3 \mathrm{H}, \mathrm{m}), 3.00(3 \mathrm{H}$, s), $3.53(1 \mathrm{H}, \mathrm{d}, J=5.7 \mathrm{~Hz}), 3.67(2 \mathrm{H}, \mathrm{brs}), 3.85-4.09(1 \mathrm{H}, \mathrm{m}), 4.26-4.70(1 \mathrm{H}, \mathrm{m}), 5.04-5.61$ $(1 \mathrm{H}, \mathrm{m}), 6.15(1 \mathrm{H}, \mathrm{d}, J=7.6 \mathrm{~Hz}), 7.13-7.26(3 \mathrm{H}, \mathrm{m}), 7.27-7.35(2 \mathrm{H}, \mathrm{m})$. MS (ESI/APCI) mass calculated for $[\mathrm{M}+\mathrm{H}]^{+}\left(\mathrm{C}_{22} \mathrm{H}_{35} \mathrm{~N}_{2} \mathrm{O}_{4} \mathrm{~S}\right)$ requires $\mathrm{m} / \mathrm{z}$ 422.6, found $\mathrm{m} / \mathrm{z} 423.2$.

\section{Methyl}

(2R,3S)-3-((methylsulfonyl)amino)-2-(((cis-4-

\section{phenylcyclohexyl)oxy)methyl)piperidine-1-carboxylate (16)}

To a mixture of $14(58 \mathrm{mg}, 0.16 \mathrm{mmol})$ and $\mathrm{Et}_{3} \mathrm{~N}(0.044 \mathrm{~mL}, 0.32 \mathrm{mmol})$ in THF $(3 \mathrm{~mL})$ was added methyl chlorocarbonate $(0.024 \mathrm{~mL}, 0.32 \mathrm{mmol})$ at $\mathrm{rt}$. The mixture was stirred at $\mathrm{rt}$ overnight. The mixture was quenched with water and extracted with EtOAc. The organic layer was separated, washed with saturated aqueous $\mathrm{NaCl}$, dried over anhydrous $\mathrm{Na}_{2} \mathrm{SO}_{4}$, and 
concentrated in vacuo. The residue was purified by column chromatography (silica gel, hexane/EtOAc, 1:1 to 0:100) to give $16(64 \mathrm{mg}, 0.15 \mathrm{mmol}, 95 \%)$ as a colorless oil. Crystallization of $\mathbf{1 6}(1.8 \mathrm{~g}, 4.1 \mathrm{mmol})$ from $\mathrm{EtOH}-\mathrm{H}_{2} \mathrm{O}$ gave $\mathbf{1 6}(1.7 \mathrm{~g}, 3.9 \mathrm{mmol}, 95 \%)$ as a white solid. ${ }^{1} \mathrm{H}$ NMR (600 MHz, DMSO- $\left.d_{6}\right) \delta 1.40-1.55(5 \mathrm{H}, \mathrm{m}), 1.56-1.73(5 \mathrm{H}, \mathrm{m}), 1.87(1 \mathrm{H}$, brd, $J=13.2 \mathrm{~Hz}), 1.96(1 \mathrm{H}$, brd, $J=13.6 \mathrm{~Hz}), 2.44-2.57(1 \mathrm{H}, \mathrm{m}), 2.83(1 \mathrm{H}, \mathrm{brs}), 2.95(3 \mathrm{H}, \mathrm{s})$, 3.40 (1H, brs), 3.53-3.62 (5H, m), 3.73 (1H, brt, $J=9.7 \mathrm{~Hz}), 3.84$ (1H, brs), 4.47 (1H, brs), 7.15 $(1 \mathrm{H}$, brt, $J=7.2 \mathrm{~Hz}), 7.18(1 \mathrm{H}$, brs $), 7.19(2 \mathrm{H}$, brd, $J=8.1 \mathrm{~Hz}), 7.27(2 \mathrm{H}$, brt, $J=7.4 \mathrm{~Hz}) .{ }^{13} \mathrm{C}$ NMR (151 MHz, DMSO- $d_{6}$, the minor rotamer's signals are marked with an asterisk) $\delta 24.05$, $24.39^{*}, 26.00,26.17^{*}, 27.60^{*}, 27.79,28.68,30.15^{*}, 37.54,38.13^{*}, 39.91,42.99,51.01,52.07$, $53.90^{*}, 54.49,61.48,61.89^{*}, 71.68,125.68,126.51,128.14,147.34,155.27^{*}, 156.08 . \mathrm{MS}$ (ESI/APCI) mass calculated for $[\mathrm{M}+\mathrm{H}]^{+}\left(\mathrm{C}_{21} \mathrm{H}_{33} \mathrm{~N}_{2} \mathrm{O}_{5} \mathrm{~S}\right)$ requires $\mathrm{m} / \mathrm{z}$ 424.6, found $\mathrm{m} / \mathrm{z}$ 425.2. mp $113{ }^{\circ} \mathrm{C}$. Anal. Calcd for $\mathrm{C}_{21} \mathrm{H}_{32} \mathrm{~N}_{2} \mathrm{O}_{5} \mathrm{~S}: \mathrm{C}, 59.41 ; \mathrm{H}, 7.60 ; \mathrm{N}, 6.60$. Found: C, 59.45; H, 7.59; $\mathrm{N}, 6.55 \cdot[\alpha]_{D}^{20}+16.3\left(c 0.1, \mathrm{CHCl}_{3}\right)$

\section{Ethyl} rel-(2R,3S)-3-((methylsulfonyl)amino)-2-(((cis-4-

\section{phenylcyclohexyl)oxy)methyl)piperidine-1-carboxylate (17)}

To a mixture of s8c $(50 \mathrm{mg}, 0.14 \mathrm{mmol})$ and DIEA $(0.071 \mathrm{~mL}, 0.41 \mathrm{mmol})$ in THF $(3 \mathrm{~mL})$ was added ethyl chlorocarbonate $(0.039 \mathrm{~mL}, 0.41 \mathrm{mmol})$ at $\mathrm{rt}$. The mixture was stirred at $\mathrm{rt}$ for $1.5 \mathrm{~h}$. The mixture was quenched with water and extracted with EtOAc. The organic layer was separated, washed with saturated aqueous $\mathrm{NaCl}$, dried over anhydrous $\mathrm{Na}_{2} \mathrm{SO}_{4}$, and concentrated in vacuo. The residue was purified by column chromatography (silica gel, hexane/EtOAc, 1:1 to 0:100) to give the racemic compound. Chiral separation (Chiralcel OJ-H $20 \mathrm{~mm} \mathrm{ID} \times 250 \mathrm{mmL}$ column $\left(\mathrm{CO}_{2} / \mathrm{MeOH} / \mathrm{Et}_{2} \mathrm{NH}, 900: 100: 1\right)$ at $\left.60 \mathrm{~mL} / \mathrm{min}\right)$ gave $17(23 \mathrm{mg}, 0.052 \mathrm{mmol}, 37 \%)$ as a colorless oil. Analytical HPLC analysis carried out on a $4.6 \mathrm{~mm} \mathrm{ID} \times 250 \mathrm{mmL}$ Chiralcel OJ-H 
column (hexane/EtOH, 600:400) at a flow rate of $1.0 \mathrm{~mL} / \mathrm{min}$ indicated that $\mathbf{1 7}$ was of $>99.9 \%$ ee. ${ }^{1} \mathrm{H}$ NMR $\left(300 \mathrm{MHz} \mathrm{CDCl}_{3}\right) \delta 1.20-1.32(3 \mathrm{H}, \mathrm{m}), 1.55-1.88(9 \mathrm{H}, \mathrm{m}), 1.95-2.16(3 \mathrm{H}, \mathrm{m})$, 2.45-2.61 (1H, m), 2.70-2.88 (1H, m), $2.99(3 \mathrm{H}, \mathrm{s}), 3.52-3.73(3 \mathrm{H}, \mathrm{m}), 3.90-4.07(2 \mathrm{H}, \mathrm{m})$, $4.08-4.25(2 \mathrm{H}, \mathrm{m}), 4.63(1 \mathrm{H}, \mathrm{d}, J=3.8 \mathrm{~Hz}), 6.04(1 \mathrm{H}, \mathrm{brs}), 7.14-7.26(3 \mathrm{H}, \mathrm{m}), 7.29(2 \mathrm{H}, \mathrm{d}, J=$ 7.2 Hz). MS (ESI/APCI) mass calculated for $[\mathrm{M}+\mathrm{H}]^{+}\left(\mathrm{C}_{22} \mathrm{H}_{35} \mathrm{~N}_{2} \mathrm{O}_{5} \mathrm{~S}\right)$ requires $\mathrm{m} / \mathrm{z}$ 438.6, found $\mathrm{m} / \mathrm{z} 439.2$.

rel-(2R,3S)- $N$-Ethyl-3-((methylsulfonyl)amino)-2-(((cis-4phenylcyclohexyl)oxy)methyl)piperidine-1-carboxamide (18)

To a mixture of s8c $(0.28 \mathrm{mg}, 0.76 \mathrm{mmol})$ and $\mathrm{Et}_{3} \mathrm{~N}(0.32 \mathrm{~mL}, 2.3 \mathrm{mmol})$ in THF $(2 \mathrm{~mL})$ was added isocyanatoethane $(81 \mathrm{mg}, 1.2 \mathrm{mmol})$ at $0{ }^{\circ} \mathrm{C}$. The mixture was stirred at $\mathrm{rt}$ overnight, quenched with water, and extracted with EtOAc. The organic layer was washed with saturated aqueous $\mathrm{NaCl}$, dried over anhydrous $\mathrm{Na}_{2} \mathrm{SO}_{4}$, and concentrated in vacuo. The residue was purified by column chromatography (silica gel, hexane/EtOAc, 1:1 to $0: 100$ ) to give the racemic compound. Chiral separation (Chiralpak IC $50 \mathrm{~mm}$ ID $\times 500 \mathrm{mmL}$ column (hexane $/ i$-PrOH, 200:800) at $60 \mathrm{~mL} / \mathrm{min})$ gave $18(0.15 \mathrm{~g}, 0.35 \mathrm{mmol}, 46 \%)$ as an amorphous solid. Analytical HPLC analysis carried out on a $4.6 \mathrm{~mm}$ ID $\times 250 \mathrm{mmL}$ Chiralpak IC column (hexane $/ i$-PrOH, 200:800) at a flow rate of $0.5 \mathrm{~mL} / \mathrm{min}$ indicated that 18 was of $>99.9 \%$ ee. ${ }^{1} \mathrm{H} \mathrm{NMR}(300 \mathrm{MHz}$, $\left.\mathrm{CDCl}_{3}\right) \delta 1.14(3 \mathrm{H}, \mathrm{t}, J=7.3 \mathrm{~Hz}), 1.60-1.74(8 \mathrm{H}, \mathrm{m}), 1.98-2.09(4 \mathrm{H}, \mathrm{m}), 2.46-2.61(1 \mathrm{H}, \mathrm{m})$, 2.74-2.91 (1H, m), $3.01(3 \mathrm{H}, \mathrm{s}), 3.26(2 \mathrm{H}, \mathrm{qd}, J=7.2,5.4 \mathrm{~Hz}), 3.50-3.70(3 \mathrm{H}, \mathrm{m}), 3.71-3.83$ $(1 \mathrm{H}, \mathrm{m}), 3.93(1 \mathrm{H}, \mathrm{dd}, J=9.3,7.6 \mathrm{~Hz}), 4.47-4.60(1 \mathrm{H}, \mathrm{m}), 4.72(1 \mathrm{H}, \mathrm{t}, J=5.1 \mathrm{~Hz}), 5.75(1 \mathrm{H}, \mathrm{d}$, $J=7.7 \mathrm{~Hz}), 7.17-7.32(5 \mathrm{H}, \mathrm{m})$. MS (ESI/APCI) mass calculated for $[\mathrm{M}+\mathrm{H}]^{+}\left(\mathrm{C}_{22} \mathrm{H}_{36} \mathrm{~N}_{3} \mathrm{O}_{4} \mathrm{~S}\right)$ requires $\mathrm{m} / \mathrm{z}$ 437.6, found $\mathrm{m} / \mathrm{z} 438.3$. 


\section{ABBREVIATIONS USED}

DMF, N,N-dimethylformamide; THF, tetrahydrofuran; dba, dibenzylideneacetone; XPhos, dicyclohexyl(2',4',6'-triisopropyl-[1,1'-biphenyl]-2-yl)phosphine; $\mathrm{Pd} / \mathrm{C}$, palladium on carbon; $\mathrm{Rh} / \mathrm{C}$, rhodium on carbon; $t$-BuXPhos, di-tert-butyl(2',4',6'-triisopropyl-[1,1'-biphenyl]-2yl)phosphine; DIEA, $\quad N$-ethyl- $N$-isopropylpropan-2-amine; DMA, $N, N$-dimethylacetamide; NaHMDS， sodium bis(trimethylsilyl)amide; DBU, 2,3,4,6,7,8,9,10-octahydropyrimido[1,2a]azepine 


\section{Calcium flux assay (in vitro agonistic activity of OX2R and OX1R) ${ }^{1}$}

hOX1R/CHO-K1 cells and hOX2R/CHO-K1 cells suspended in Ham's F-12 medium (Fujifilm Wako Pure Chemical Co.) supplemented with $100 \mathrm{U} / \mathrm{mL}$ penicillin-streptomycin and 10\% FBS were plated in blackwalled clear-bottomed 384-well plates (Corning, NY, USA) at 10000 cells/well and in black-walled clear-bottomed 96-well plates (Corning) at 45000 cells/well, respectively. The plated cells were grown overnight at $37{ }^{\circ} \mathrm{C}$ in the presence of $5 \% \mathrm{CO} 2$. The following day, the medium was removed, and the cells were incubated with assay buffer (HBSS with 20mM HEPES, pH 7.4, and 0.1\% fatty acid free BSA) containing $2.5 \mu \mathrm{g} / \mathrm{mL}$ Fluo-4 AM (Cat.\# F312, Dojindo Laboratories, Kumamoto, Japan), $1.25 \mathrm{mM}$ probenecid (Dojindo Laboratories), and $0.08 \%$ Pluronic F127 (Dojindo Laboratories) for $30 \mathrm{~min}$ at $37{ }^{\circ} \mathrm{C}$ in the presence of $5 \% \mathrm{CO} 2$. After incubation, the cells were stimulated with test compounds in the assay buffer. Calcium mobilization was measured using an FDSS/ $\mu$ CELL (Hamamatsu Photonics K.K., Shizuoka, Japan). The responses to $0.11 \%$ DMSO and $100 \mathrm{nM} \mathrm{OX-A}$ were used to represent the $0 \%$ and $100 \%$ responses, respectively. 


\section{Transcellular transport study using a transporter-expression system}

Human MDR1-expressing LLC-PK1 cells were cultured as reported previously with minor modifications. ${ }^{2}$ The transcellular transport study was performed as reported previously. ${ }^{2}$ In brief, the cells were grown for 7 days in an HTS Transwell 96-well permeable support (pore size, 0.4 $\mu \mathrm{m}$; surface area, $0.143 \mathrm{~cm}^{2}$ ) with a polyethylene terephthalate membrane (Corning Life Sciences, Lowell, MA, USA) at a density of $1.125 \times 10^{5}$ cells/well. The cells were preincubated with M199 at $37{ }^{\circ} \mathrm{C}$ for $30 \mathrm{~min}$. Subsequently, transcellular transport was initiated by the addition of M199 either to apical compartments $(75 \mu \mathrm{L})$ or to the basolateral compartments $(250 \mu \mathrm{L})$ containing 10 $\mu \mathrm{M}$ digoxin, $200 \mu \mathrm{M}$ lucifer yellow as a marker for the monolayer tightness, and $10 \mu \mathrm{M}$ test compounds and then terminated by the removal of each assay plate after $2 \mathrm{~h}$. The aliquots $(25$ $\mu \mathrm{L})$ in the opposite compartments were mixed with acetonitrile containing alprenolol and diclofenac as an internal standard and then centrifuged. The compound concentrations in the supernatant were measured by LC-MS/MS. The apparent permeability $\left(\mathrm{P}_{\text {app}}\right)$ of test compounds in the receiver wells was determined, and the efflux ratio for the MDR1 membrane permeability test was calculated using the following equation:

Efflux ratio $=P_{\text {app,BtoA }} / P_{\text {app,AtoB }}$

where $P_{\text {app,AtoB }}$ is the apical-to-basal passive permeability-surface area product and $P_{\text {app,BtoA }}$ is the basal-to-apical passive permeability-surface area product. 


\section{Measurement of plasma and brain concentration of compound 16 in mice}

The aliquots of the brain homogenate were mixed with acetonitrile containing internal standard. The mixtures were centrifuged. The supernatants were diluted with solvents for LC-MS/MS (mobile phase A: $10 \mathrm{mM}$ ammonium formate/formic acid (100/0.2, v/v), mobile phase B: acetonitrile/formic acid (100/0.2, v/v)). The diluted solutions were injected into LC-MS/MS (API5000, AB Sciex, CA) equipped with Shimadzu Shim-pack XR-ODS $(2.2 \mu \mathrm{m}, 2.0 \times 30 \mathrm{~mm}$, Shimadzu Corporation, Japan) at $50{ }^{\circ} \mathrm{C}$. Analyst software TM (version 1.4.2) was used for data acquisition and processing.

Ethics Statement. The care and use of the animals and the experimental protocols used in this research were approved by the Experimental Animal Care and Use Committee of Takeda Pharmaceutical Company Limited. 


\section{Evaluation of wakefulness time measurement of compound 16 in mice}

ICR mice were obtained from CLEA Japan Inc. (Tokyo, Japan). Mice were housed in groups of 4 per cage in a light controlled room (12 h light/dark cycle with lights on at 07:00 h). Food and tap water were provided ad libitum. The care and use of the animals and the experimental protocols in this study were approved by the Institutional Animal Care and Use Committee of Takeda Pharmaceutical Company Limited. Implantation of EEG electrodes was performed as described previously. ${ }^{1}$ Compound 16 at $3 \mathrm{mg} / \mathrm{kg}$ suspended in $0.5 \%$ methylcellulose saline was administered subcutaneously to mice at zeitgeber time 5 (ZT5) in a volume of $10 \mathrm{~mL} / \mathrm{kg}$ body weight, and then EEG was recorded. EEG analysis was performed with data collected during the first $3 \mathrm{hr}$ after administration of Compound 16. Data were presented as the mean + standard error of the mean (S.E.M.). The statistical significance between two groups was determined by paired t-test with significance set at $P<0.05$.

Ethics Statement. The care and use of the animals and the experimental protocols used in this research were approved by the Experimental Animal Care and Use Committee of Takeda Pharmaceutical Company Limited. 


\section{${ }^{1} \mathrm{H}$ NMR and ${ }^{13} \mathrm{C}$ NMR charts of compound 16}

\section{1) $1 \mathrm{H} \mathrm{NMR}$}

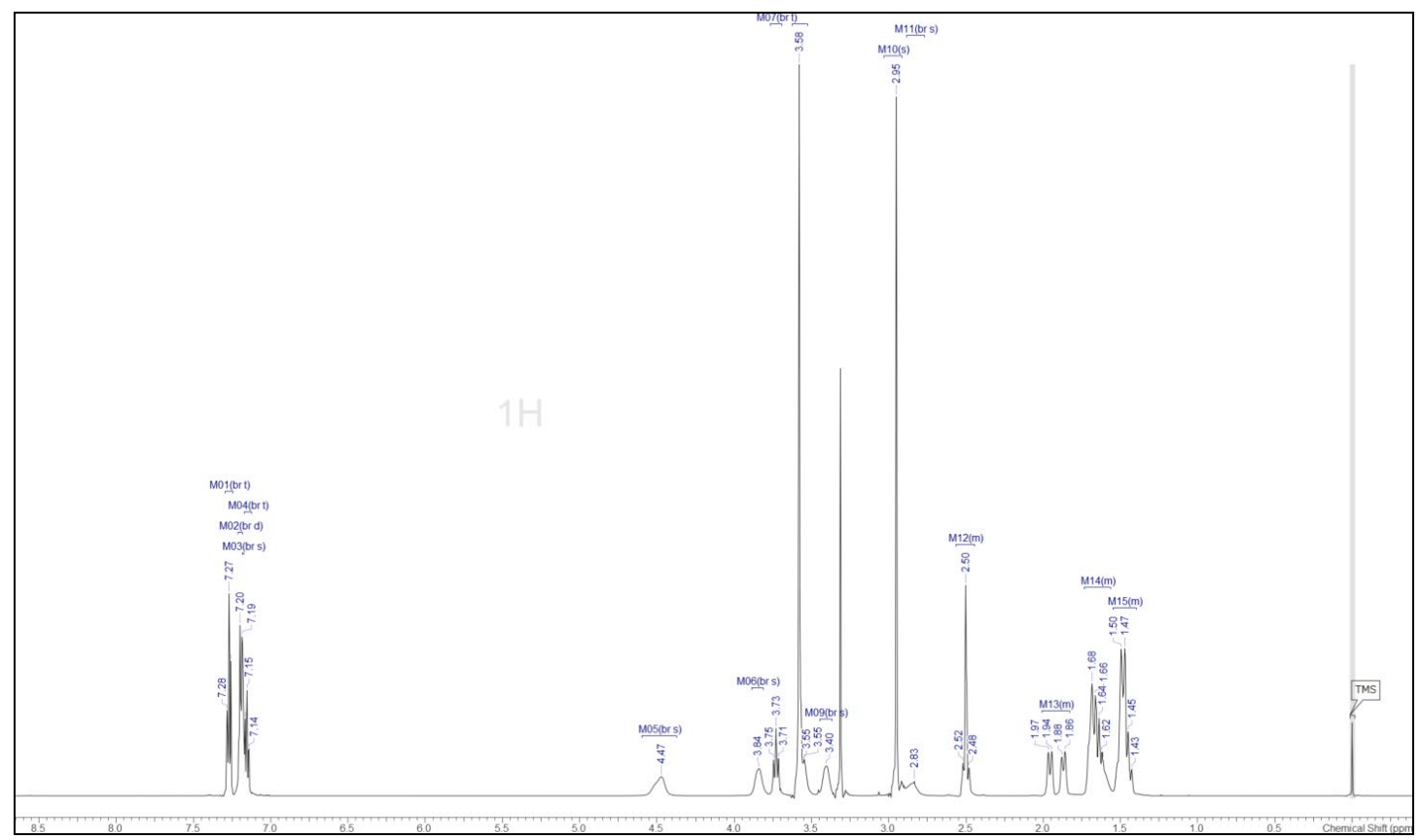

2) $13 \mathrm{C} \mathrm{NMR}$

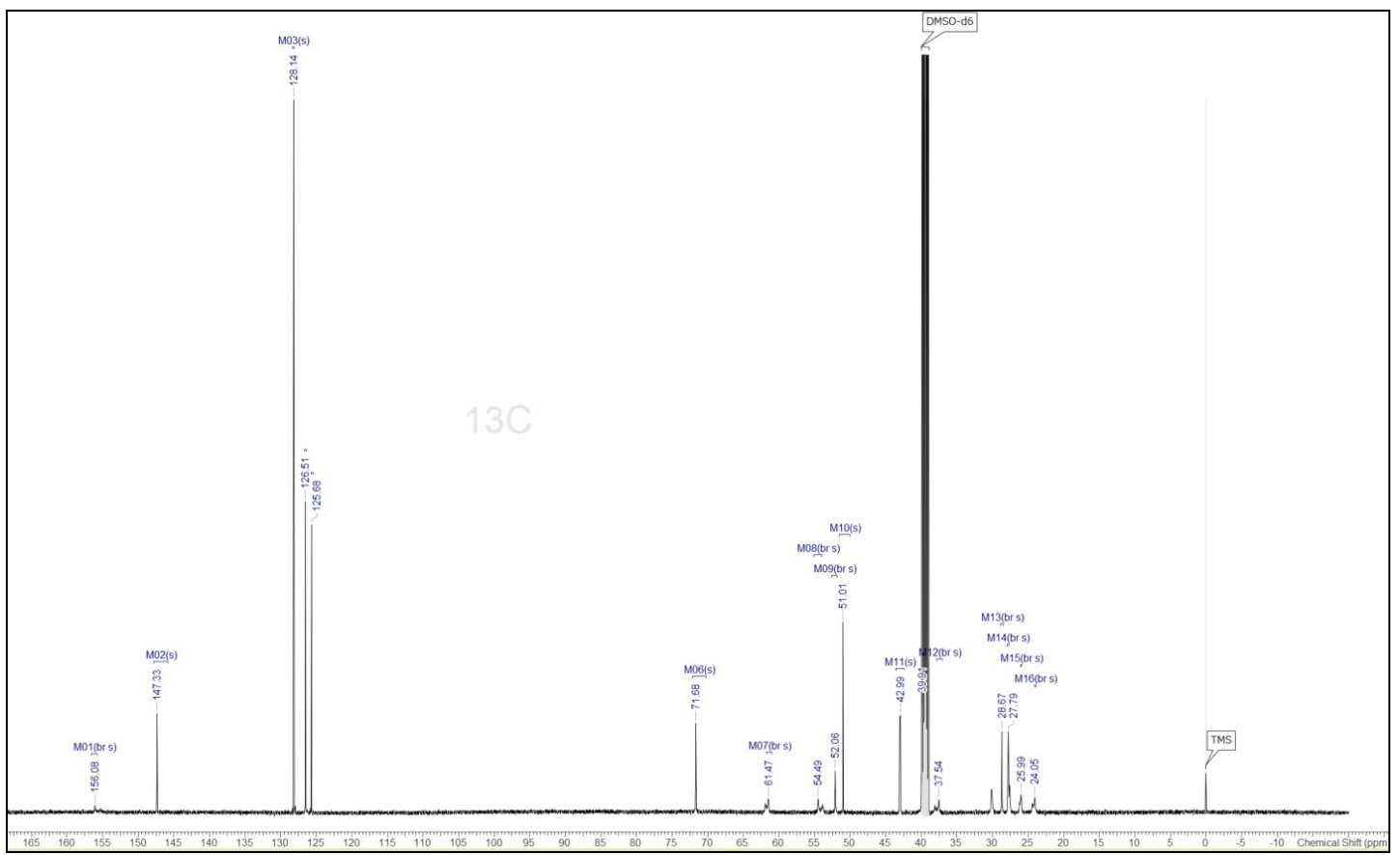




\section{Single-crystal X-ray structure analysis of compound 16}

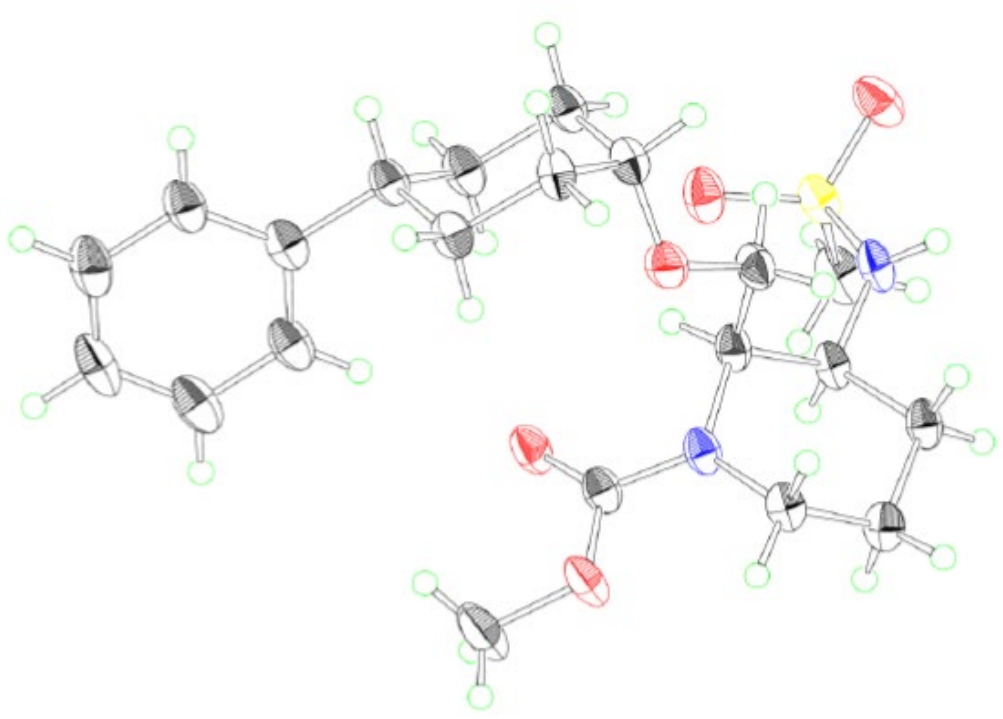

Figure S1. ORTEP of compound 16, thermal ellipsoids are drawn at 50\% probability.

Crystal data for compound 16: $\mathrm{C}_{21} \mathrm{H}_{32} \mathrm{~N}_{2} \mathrm{O}_{5} \mathrm{~S} M W=424.55$; crystal size, 0.24 x 0.12 x $0.05 \mathrm{~mm}$; colourless, plate; monoclinic, space group $P 2_{1}, a=9.66931(13) \AA, b=11.39460(14) \AA, c=$ $10.36070(10) \AA, \alpha=\gamma=90^{\circ}, \beta=106.5990(12)^{\circ}, V=1093.95(2) \AA^{3}, Z=2, D x=1.289 \mathrm{~g} / \mathrm{cm}^{3}, T=$ $100 \mathrm{~K}, \mu=1.599 \mathrm{~mm}^{-1}, \lambda=1.54184 \AA, R_{1}=0.0525, w R_{2}=0.1427, S=1.046$, Flack Parameter ${ }^{3}=$ $0.01(2)$

All measurements were made on a Rigaku XtaLAB P200 diffractometer using multi-layer mirror monochromated $\mathrm{Cu}-\mathrm{K} \alpha$ radiation. The structure was solved by direct methods with SHELXT-2018/2 ${ }^{4}$ and was refined using full-matrix least-squares on $\mathrm{F}^{2}$ with SHELXL-2018/3. ${ }^{5}$ All non-H atoms were refined with anisotropic displacement parameters.

CCDC 2111149 for compound $\mathbf{1 6}$ contains the supplementary crystallographic data for this paper. These data can be obtained free of charge from The Cambridge Crystallographic Data Centre via http://www.ccdc.cam.ac.uk/structures. 


\section{References}

(1) Yukitake, H.; Fujimoto, T.; Ishikawa, T.; Suzuki, A.; Shimizu, Y.; Rikimaru, K.; Ito, M.; Suzuki, M.; Kimura, H. TAK-925, an orexin 2 receptor-selective agonist, shows robust wakepromoting effects in mice. Pharmacol. Biochem. Behav. 2019, 187, 172794.

(2) Takeuchi, T.; Yoshitomi, S.; Higuchi, T.; Ikemoto, K.; Niwa, S.; Ebihara, T.; Katoh, M.;

Yokoi, T.; Asahi, S. Establishment and characterization of the transformants stably-expressing MDR1 derived from various animal species in LLC-PK1. Pharm. Res. 2006, 23, 1460-1472.

(3) Parsons, S.; Flack, H. D.; Wagner, T. Use of intensity quotients and differences in absolute structure refinement. Acta Cryst. B, 2013, 69, 249-259.

(4) Sheldrick, G.M. A SHELXT: Integrating space group determination and structure solution. Acta Cryst. A, 2014, 70, C1437.

(5) Sheldrick, G.M. A short history of SHELX. Acta Cryst. A, 2008, 64, 112-122. 